\title{
An exploratory and comparative analysis between bottom-up and top-down approaches for a spatialized construction of a regional Input-Output matrix ${ }^{1}$ Normand Eduardo Asuad Sanén ${ }^{2}$ \\ Universidad Nacional Autónoma de México \\ Centro de Estudios de Desarrollo Regional y Urbano Sustentable, CEDRUS José Manuel Sánchez \\ Centro de Estudios de Desarrollo Regional y Urbano Sustentable, CEDRUS
}

(Recibido 2 de junio 2017, aceptado 13 de octubre 2017.)

DOI: http://dx.doi.org/10.21919/remef.v13i2.273

\begin{abstract}
The purpose of this paper is to explore and apply a methodology for the construction of a regional spatial input-output matrix, using a bottom-up approach, compared to the top-down of the Sonora 2008 regional matrix. We use the methodology proposed by Flegg for the estimation of regional matrixes, spatializing it with limited information. In addition, we compare the two regional matrixes constructed by identifying the type of productive sectors, their economic links and multiplier effects, highlighting the application of the statistical method of principal components. It should be clarified that the spatialized analysis of input -output matrixes has not been addressed in the literature hence the importance of its analysis. The results show either at spatial and sectoral levels, that the sectors and economic structure that come from the regional matrix constructed from bottom-up approach are theoretically and statistically coherence, contrary to what happens with the regional matrix constructed from top-down approach, which allow us to conclude the importance of considering economic space as a fundamental element in the construction of regional input-output matrices.
\end{abstract}

JEL Classification: R15.

Key words: Regional input-output matrixes, bottom-up approach and top-down approach

\footnotetext{
${ }^{1}$ This essay is part of the project "Modelo UNAM para construir, con metodología de abajo hacia arriba, matrices de insumo-producto (MIPR) por entidad federativa para México 2008" ÜNAM Model to construct, with a "bottom-up" methodology, input-output matrices by state in Mexico, 2008"financed by CONACYT-INEGI, sectoral fund. Request: 268424.In fact this article is the first phase of the methodology proposal that we are developing for the construction and implementing an input -output regional matrix using a bottom-up approach and it comprises a set of exploratory analysis.

We are grateful for the comments and suggestions given by the Journal referees. We want also to mention our recognition for the collaboration of students and member professors participating in CEDRUS; without them, the creation of this article would not have been possible; particularly to Karina Garduño Maya, Krista Zafra Garcia, Alejandra A. Ibañez Tercero, Sergio Rodriguez, Francisco Alfredo Garcia, and Adrian Garcia. Further, we are very grateful to Dra. Maria Dolores Sanchez for its statistical comments and to Dr. William Sughrua and to William Ismael Sughrua Martinez for the English revision.

${ }^{2}$ Edificio de Posgrado de la Facultad de Economía, Ciudad Universitaria. Circuito Mario de la Cueva sin número, Zona Cultural, México, D.F. C.P. 04510, Cubiculo12 .Teléfono 562218 88, etx 48926. Email: nasuad@yahoo.com. normand.asuad@gmail.com. cedrus@economia.unam.mx; Email: Jose Sanchez :sanchezgamboajm@gmail.com.
} 


\title{
Un análisis exploratorio y comparativo entre los enfoques de bottom-up y top-down para una construcción espacial de una matriz regional Input-Output.
}

\author{
Resumen \\ El propósito de este ensayo es explorar y aplicar una metodología para la construc- \\ ción de una matriz regional de insumo-producto espacializada, utilizando un enfoque \\ de abajo hacia arriba, comparado con el de arriba hacia abajo de la matriz regional \\ de Sonora 2008. Para ello se utiliza la metodología propuesta por Flegg para la esti- \\ mación de matrices regionales, espacializandola con información limitada. Además se \\ comparan ambas matrices regionales construidas mediante la identificación del tipo de \\ sectores productivos, sus vinculaciones económicas y efectos multiplicadores, destacan- \\ do la aplicación del método estadístico de componentes principales. Cabe aclarar que \\ el análisis espacializado de matrices de insumo producto, no ha sido abordado en la \\ literatura de ahí la importancia de su análisis. Los resultados muestran a nivel espacial \\ como sectorial, que los sectores y estructura económica que provienen de la matriz re- \\ gional construida desde abajo es coherente teórica y estadísticamente, contrariamente \\ a lo que sucede con la matriz regional construida desde arriba, lo que permite concluir \\ la importancia de considerar el espacio económico como elemento fundamental en la \\ construcción de matrices regionales de insumo-producto. \\ Classification JEL: R15. \\ Palabras claves: Matrices regionales de insumo-producto, enfoque de abajo hacia arri- \\ ba, enfoque de arriba hacia abajo
}

\section{Introduction}

The construction of a regional I-O matrix can be actually constructed using regional primary data (survey method), although it is costly and time consuming and therefore, rarely used at the regional level. More frequently, non-survey methods, which rely on various techniques that adjust a national I-O matrix, are used. According to Richardson (1972), the derivation of these methods is based on various secondary sources of statistical data applied to the national model. Several methods have already been proposed and are nowadays applied for the construction of regional matrices. However, the use of hybrid methods is stressed since they combine both survey and non-survey approaches through the use of specific data and information from small scale surveys and general statistical data.

This last approach is currently considered the most feasible to derive regional I-O matrices (Lahr, 2001), thus, numerous versions of hybrid regionalization methods have been developed (Lahr, 1993). Furthermore, the hybrid approach is classified into two categories, depending on the origin of the information: 1 . The top-down approach if the construction of the regional matrix is based on a national I-O matrix and 2. The bottom-up approach, when the construction of the regional matrix uses information coming from the respective region. (West, 1990).

As already mentioned, the construction of regional I-O matrices is usually modeled after national matrices, and they are considered as an analytical tool 
for the formulation of growth and regional development policies. However, their results are highly aggregated, leaving aside the spatial interdependencies that characterize the real behavior of a regional economy. Furthermore, top-down results do not capture the spatial heterogeneity of the intra-regional structure and its fragmented and partial economic interactions, normally taking place in different locations within a region.

The international literature on regional matrices construction, despite showing an interest for regional matters and their efforts to apply it to the regional field, lacks a spatialized regional approach, since their first applications. The first studies were made by Isard (1951) and Leontief (1955). Then came the studies of Leontief and Strout (1963), Morrison (1974), Morrison and Smith (1974), Round (1983) and Richardson (1985) Miller and Blair (1985), Hewings and Jansen (1986). ${ }^{3}$

The main focus of analysis of these models is the differentiation of the number of regions: An isolated region, two regions and multiple regions, and then focusing in the challenge of creating multiple regional models. They assume that the spatial disaggregation of a region and the use of political spatial units, as representative of economic spatial units are not central problems for the construction of regional I-O matrices.

Nowadays, the problem remains very similar. Given the restricted available regional information ${ }^{4}$, during the last 20 years, the debate in the literature has been centered on techniques and alternative methodologies for the application of the top-down approach for the construction of regional I-O matrices.

The debate is then focused only in how a regional I-O matrix should be constructed with hybrid methods from a top-down perspective, focusing on the one hand, on the estimation of regional purchases and sales, relying mainly on the 1995 and 1997 Flegg's location quotient. On the other hand, the need to improve the accuracy of Stones 1969 RAS algorithm and the traditional location quotients is stressed. As Michael Lahr (1993), states, hybrid model construction should pursue a most accurate non-survey model of a region as possible -using adequate regional purchase coefficients and minimizing data aggregation.

In a similar fashion, the studies of this topic in México, have been oriented to the application of the top-down approach mainly by using Flegg and RAS methods for the construction of regional I-O matrices, basically to most of Mexican states, and other regions and municipalities. Among the most important researches, we have the following: (Dávila, 2002), (Fuentes and Brugués, 2001); (Calicó et al, 2003), (Fuentes, 2003 y 2005), (Armenta, 2007), (Cruz, 2008), (Chapa, 2009), (Rosales, 2010), (Aroche Fidel, 2013) and ( Dávila, 2015).

Without any doubt, these works, just like those at the international level are very important applied researches that try to improve the knowledge related to the construction of regional I-O matrices in Mexico, through a top-down

\footnotetext{
${ }^{3}$ See Miller and Blair (1985, p. 69-77).

${ }^{4}$ See (Lahr 1993), (Brand S, 1997), (MCcan and Dewhurst, 1998), (Lahr and Steven, 2002), (TohmoT,2004), (Lehtonen O. and Tykkyläinen M, 2014) and (Kowalewksi J. 2015).
} 
approach. However, it is evident for an academic and policy-making standpoint, that there is a need, both nationally and internationally, for methodologies that could integrate spatial elements of the economic behavior of regions in the construction of I-O matrices, in order to have a more precise analysis and a closer view of the real performance of a region, as well as to promote better policymaking decisions in terms of regional growth and development.

Consequently, to address the challenge of the construction of a spatialized regional input-output matrix we propose a spatial, theoretical and methodological approach from a bottom-up perspective, first, with the use of spatial economic units, as the foundations of the construction of regional matrixes, instead of administrative political entities, such as states, municipalities, provinces or counties.

In this approach we consider that the traditional assumptions in the construction of regional I-O matrices imply that the spatial dimension of a regional economy is not determinant for the construction of I-O matrixes and their models. Consequently the regional economy is economically interpreted without space, merely as a sectorial aggregate in a point of a space, which means either that the link between spatial economic location between production and consumption areas in a region does not affect the regional economic behavior or that production and consumption are located in the same place, which is completely inadequate and unreal.. Furthermore, it is assumed that the economic areas are bounded to the political spatial units. Consequently, the construction of regional I-O matrixes is based on the assumptions of sectorial aggregation and its location on a spatial unit, without considering their economic spaces.

Therefore, we promote the development of a new research agenda in the construction of regional I-O matrices based on the spatialization approach that we mentioned above. However, it is important to mention that it is still an exploratory research carried out by the application of different methodologies based on bottom-up approaches, as an attempt to build a spatial economic methodology for the construction of regional I-O matrices based on the approach of the spatial dimension of the economy.

This essay is part of that research agenda, which in this case, is based on the application of the Fleggs Webber and Elliot bottom-up methodology (1995 and 1996$)^{5}$, with a complementary spatial and statistical assessment of their advantages and a comparison with the top-down approach ${ }^{6}$.

Hence, our main concern in this article, is to develop and implement a methodology for the construction of a spatialized regional I-O matrix, in order to give some empirical evidence of the spatial differences and their effects on the

\footnotetext{
${ }^{5}$ See Attachment III. The Methodology of Flegg, Weber and Elliot.

${ }^{6}$ This analysis is a research complement of the article, Asuad and Sanchez, 2016 " A methodological proposal for the construction of a regional input-output matrix using a bottom-up approach and its statistical assessment, published in Investigacion económica Review. Nevertheless, this article differs either in the methodology for the construction of the regional IO matrix and in the type of the assesment, however it keeps the focus on the spatial approach based on the bottom-up perspective for the construction of a regional IO matrix.
} 
economic linkages of a region when using both approaches. As a case study we used the state of Sonora, where we compare both matrices.

The spatial disaggregation has the region as its basis, through the identification and delineation of ten spatial economic functional units (SEFUs), which we define as economic sub-regions. This analysis required the construction of ten sub-regional input-output matrices, one for each sub region, with a size of $20 \mathrm{x}$ 20 economic sectors. This lead to the creation of 100 matrices: 10 sub-regional and 90 inter sub-regional matrices, while the construction of the top-down regional input - output matrix (constructed by the Government of Sonora), is done in an aggregate way, using Flegg ${ }^{6}$ methodology ${ }^{7}$, without considering the intra - regional structure of the state.

It is important to mention that, despite the fact that the analysis is done using the state of Sonora, a political spatial unit, the construction of the regional I-O matrix under bottom-up approach was created through the functional integration of the 10 economic sub-regions and their economic behavior, that were identified in the area. As already mentioned, we constructed 10 sub-regional I-O matrices, integrated by their economic interdependencies, therefore the Sonora bottom-up regional matrix is an outcome of the aggregation of its economic sub regions, whereas, the regional top-down matrix was created based on political area of Sonora.

For the comparison of both matrices, we used two comparative analyses. The first one is spatial, oriented to the comparison between the economic linkages identified in both matrices with those that exist at the sub-regional level. For this purpose, we use the traditional approach of Chenery and Watanabe ${ }^{8}$ (1958), and we compare their classification on both matrices, with the economic specialization and diversification to economic specialization and diversification of the economic sub regions, so as to find a contrast between the economic linkages arising from both approaches and the existence of spatial economic linkages within the economic sub-regions with the expectation to have a preliminary evidence of the no coincidence between the classified regional aggregated economic linkages coming from the top-down approach and those identified at spatial level.

The second comparative analysis is sectorial, and complements the first one, given that it attempts to find statistical evidence to support our hypothesis concerning the inefficacy of the top-down approach to capture observed economic linkages in a region. We do this, first, by applying the methodology of Feser and

\footnotetext{
${ }^{7}$ See Secretaria de Economía, Gobierno del Estado de Sonora, 2011, Matriz de Insumoproducto para el Estado de Sonora, Actualización y Regionalización estadística, Sonora Hermosillo, 30 de Julio de 2011

${ }^{8}$ We chose the traditional approach of Chenery and Watanabe for the characterization of the economic linkages of the sectors of economic activity because it gave us the essential elements that our analysis required according to our goal. However, it is noteworthy that there are a variety of studies that propose different classifications of productive chains as key sectors, independent bases or drivers, such as: Rasmussen (1956), Chenery and Watanabe (1958), Hazari (1970) Cella (1984), Sonis et al. (1995), and Van der Linden Dietzenbacher (1997), among others. See also Soza and Ramos Carvajal (2010).
} 
Bergman (2009) that identifies clusters and the economic branches that integrate them, as well as a statistical measurement of their economic linkages. The first part of the analysis is concerned with the presence and economic link of the identified clusters and the second one, is related to the multiplier effects of the type of economic linkages that arise from their economic performance, using multipliers indexes of output and demand. (Miller and Blair, 2009) and (K. Burgos, 2007). Both analyses are based on the principal components analysis (PCA) whose main features are presented in attachment 4.

Therefore, this paper consists of five parts: (1) Interpretation and methodology; (2) the description of the main natural features of Sonora (3) the comparative analysis of both regional matrices, taking into account their economic linkages and pointing out their differences and associations with the spatial location of the economic activities within the region; (4) The spatial and statistical measurement of the economic linkages and their multiplying effects of the identified clusters according to both approaches; and (5) Conclusions.

\section{Interpretation and methodology}

According to the theoretical and methodological approach of the economic concentration of the spatial dimension of the economy, a perspective that we have been developing, it is assumed that economic concentration in space causes the formation of economic spatial units that determine and characterize the spatial structure and the behavior of the economy in a geographic space. In a generic way, these spatial units are defined as functional spatial economic units ${ }^{9}$, which are the result of the economic growth and development in space (Asuad, 2001, 2007 and 2014).

We assume that economic growth in the national and international space is not homogeneous or politically bounded to states nor municipalities; on the contrary, the spatial distribution of economic activity has created its own economic spatial units, economic regions and territories, which basically conform a set of market areas that theoretically are integrated by an economic center and its periphery. The economic center or node is highly concentrated with the

\footnotetext{
${ }^{9}$ Generally speaking, in the regional and urban literature there is a consensus on the concept of functional regions, which are defined as the spatial units that result from the organization of economic and social relationships in space. Theoretically, this concept has been treated through different perspectives: theory of location, theory of markets areas, theories of poles of economic growth along with their debates in explaining urban territories, especially from Christaller, (1933) and Losch ,(1944) as well as in current urban policy issues (e.g., OECD, 2002). According to our conception, the essential aspect of functional economic regions is the identification of economic activities in space through its location and economic sectorial characteristics, as well as in the role and interactions they establish, giving rise to a structure of economy on space, which leads to the creation and development of an economic spatial unity. (See Asuad (2015) and OECD (2002). For specific economic functions in a city, see McDonald (1997). However, there are different techniques for the identification and measurement of the economic spatial functional region: gravity models, labor market models and commercial interactions areas. But we have developed a methodology for the identification and analysis of these units and their economic interactions through the identification of the sub-regional productive chains, whose details are presented in Attachment V.
} 
main economic activities and most of the regional population lives there. Therefore, it is relevant since most of economic interactions are carried out there, as well as production, exchange and consumption of a region. Thus, a node or hub is defined as a site or place, whose economy is characterized by its economic dominance and connection with a set of minor economic sites that interact and compete with each other. An economic site is defined as a place on the economic space, where economic activities are highly concentrated and from which a set of economic impulses are exerted through economic exchanges; this guides the spatial economic behavior as a whole.

The economic nodes are spatial economic subunits distributed in a given geographic or political space, and are characterized by their extremely dense economic activity and their population concentration. Indeed, they behave as the centers of a given market area where most of the spatial concentration of production and consumption is located. Furthermore, they are related through the economic activities carried out with their areas of influence, represented by the economic flows established among them. The economic importance of nodes depends on their economic interaction, which is an outcome of the type of connection and market relationships they established. These can be characterized as economic complementarities or competition among themselves, or just a mixture of both economic interactions. So, if these interactions were relevant, they would lead to structure sub economic spaces, which as a whole integrate the economic space, or in other words a set of economic sites and their economic interactions in a given geographic space.

Economic space, in order to exist, requires at least the existence of a pair of economic sites interacting with each other. Of course, this does not coincide with any geographic or political space, despite their influence on the economic decision-making process. Therefore, economies based on market behavior and territorial development defines how the economy as a whole is structured in space. The role of the state as a normative institution that regulates and guides market economic behavior, depends on its political and economic actions as well as its orientation. Thus, the behavior of the market economy, territorial development and eventually, the political economy of the state, are the main factors that define how the economy in space is structured.

This interpretation is related to the approach of the spatial dimension of the economy where the concept of economic space and its derivative categories: economic territory and economic region, which are the essential ingredients of our theoretical perspective.

The economic territory is defined as the product of the origin and development of the economic activity on space and it is expressed through the economic uses of land, which in an aggregated way can be synthetized in the creation of cities and their development. On the other hand, economic regions are related to the spatial functional economic behavior based on the center-periphery model. This is the result of the creation of market areas, and it is characterized by the spatial economic distribution on space, based on the creation of an economic 
center, where a great part of the production and consumption takes place and interacts with its area of influence, conformed by a set of economic sites. It is evident then, that, in territorial terms, the economic center is characterized by the existence of the main city in the region, while the territorial attributes of its periphery are the minor cities or localities that are economically connected through the network of transportation and communication systems. Finally, an economic region is an economic space integrated by the main city and the system of localities that interact with each other. Therefore, we assume that the economic interactions on space are the result of market transactions, characterized by sectorial economic behavior and their synergy with the natural and territorial space in a given area. This leads to the formation of the economic space and in turn develops a system of cities and localities that are economically related through the network of transportation that links them.

According to the above interpretation the methodology for the construction of a regional input-output matrix from bottom-up, is presented in diagram 1.

Diagram 1: Methodology for the construction of the I-O regional matrix and analysis of the essay

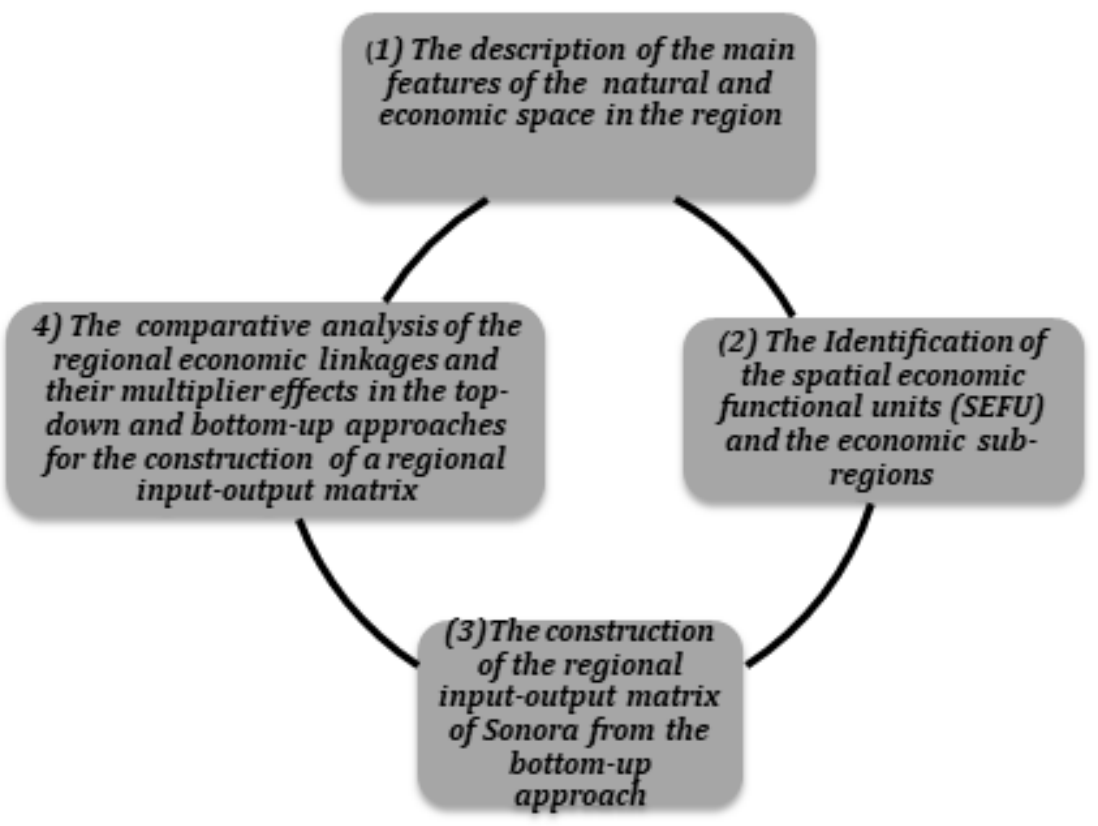

Source: Own elaboration 


\section{The description of the main features of the natural and economic space in the region}

The first step is the analysis of the delineation of the political borders and of the main natural and economic attributes of this political space. To begin with, we describe the geographical and political limits of Sonora, emphasizing the differences within the borders of its natural space and the obvious advantages that natural resources and infrastructure facilities have for population settlement and economic development. Then, we describe the economic and population nodes as well as its spatial location, economy and population size through the use of a set of indices and the following variables: population, employment and value added. This analysis is complemented with the inclusion of the road network, showing how it articulates the nodes. As a result, we characterize the nodes and their physical contiguity as well as their economic interaction through the road network of the region. . Finally we present the main economic features of the region, identifying the concentration of economic activity and population in the main nodes of the economic sub regions and their economic specialization and diversification.

\subsection{Political and natural space ${ }^{10}$}

Sonora is the second largest state in Mexico, with $9.2 \%$ of the total territory. However, it is only has $2.1 \%$ of the national population. It is located in the northwest corner of the country, bordered to the north by the United States, mostly with Arizona with 568 kilometers and 20 kilometers with New Mexico. It borders Chihuahua to the east, Sinaloa to the south and Baja California and the Gulf of Mexico to the west. The Sonoran territory is divided into two major physiographic zones: (1) The eastern mountain range Sierra Madre Occidental, which is an extension of the North American Rocky System and occupies $49 \%$ of the state; and (2) the plain located to the east towards the Gulf of California which accounts for the other $51 \%$. However, most the land is dessert (48\%) and dry $(46 \%)$ and only a very small portion is warm and humid.

Therefore, water scarcity is one of the main economic problems of Sonora. Dams and irrigation districts have been built along the main hydrographic basins in order to counteract this problem. In the region, three are the most important basins: Sonora, Yaqui and Mayo which are drained by the rivers of the same name. These run from north to south, originating in the mountains towards the Gulf of California. Nevertheless, the Yaqui and Mayo rivers are based on the main catchment area in the southwest. They influence $42 \%$ of Obregon and Navojoa, $18 \%$ of Hermosillo. However, it is important to mention that the dam system of the Yaqui River irrigates $50 \%$ of the cultivated land of the state, which by the way, has the most productive agricultural land in the country. Next in importance is the Mayo river irrigation system in the south of the Yaqui Valley (See map 1).

${ }^{10}$ Own estimate, based on INEGI. Anuario estadístico y Geografía de Sonora 2014. 
Hence, it is clear that Sonora has remarkable differences concerning natural and infrastructure facilities at the sub-regional level, highlighting mainly the advantages of the extreme southwest y central part of the Region, which are a hint of the advantages offered by these geographical areas for human settlements and for the development of economic activity in the region.

Map 1. Physiography and main rivers of Sonora

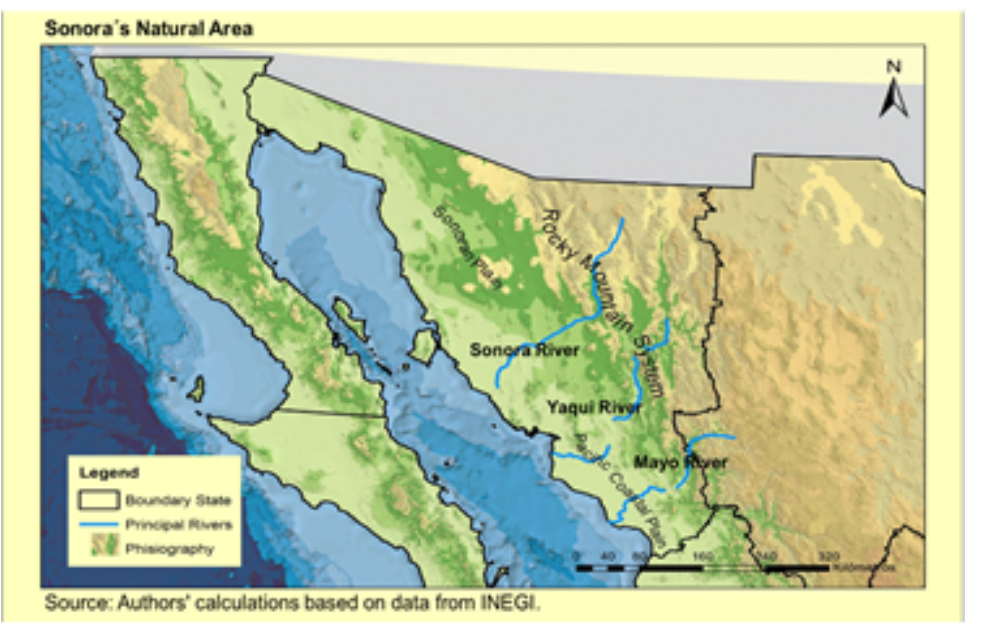

Source: Author's calculations based on data from INEGI.

2.2 Urban developments and their spatial distribution ${ }^{11}$ Regional and territorial development in Sonora is characterized by its urban spatial structure and transport network that links the cities. Nevertheless, it is characterized by its uneven urban distribution, due to the formation of an urban hierarchical system in which six cities concentrate $60 \%$ of the population. In order of importance, Hermosillo (30\%), Ciudad Obregón (12.8\%), Navojoa (4.9\%), Guaymas-Empalme (6.7\%), Nogales $(9.1 \%)$ and San Luis Río Colorado (6.8\%). Furthermore, the advantage offered by the areas for population settlement is evident. Actually, the most important urban areas are in the central and southwest areas with $57.4 \%$ of the regional population, whereas the border area accounts for only $5.8 \%$

Thus, it is easy to see the coincidence between the natural and infrastructure advantages of these areas, mentioned above and their relationships with their demographic patterns. The main population settlements are in the center and southwest with $57.4 \%$ of the population while the border area only accounts for $5.8 \%$.

${ }^{11}$ Own estimation based on INEGI. Anuario estadístico y Geografía de Sonora 2014. 
The territorial and spatial distribution of Sonora is characterized, on the one hand, by a system of prominent cities in the central plain where the regional urban population and a few border cities are concentrated. On the other hand, a pattern of huge spatial dispersion is found mainly in the mountainous area of the state. So, the network of cities forms two main corridors: (1) the south-central corridor that includes Obregon City, Hermosillo, Guaymas and Navojoa; and (2) the border corridor that runs from east to west with Agua Prieta, Nogales, Sonoita and San Luis Rio Colorado. This can be seen in Map 2.

Map 2. Location of the main cities of Sonora

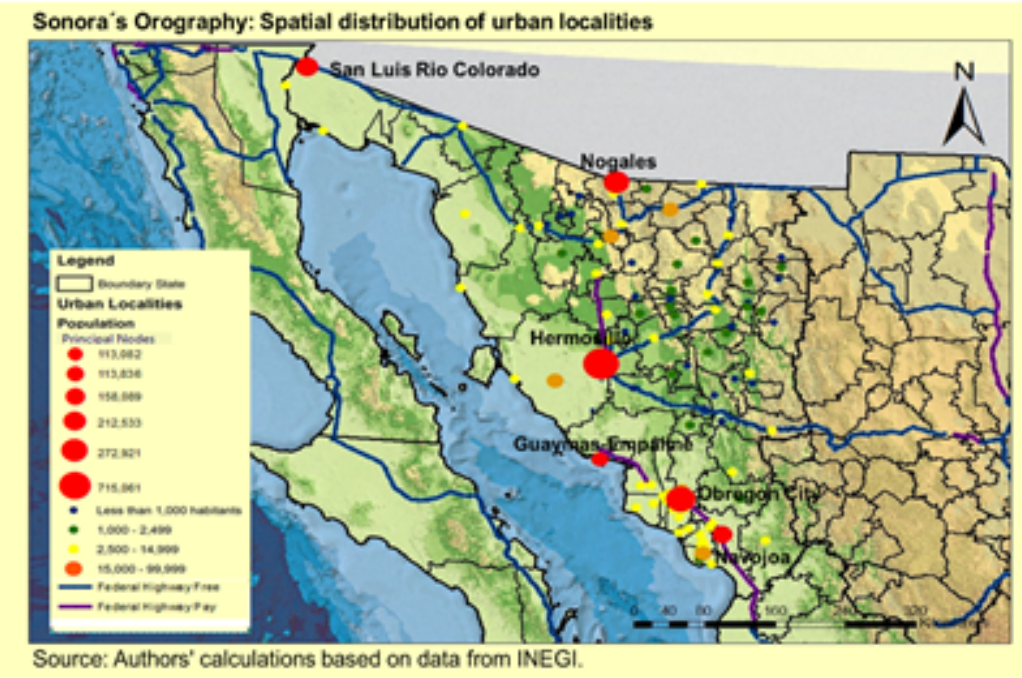

Source: Author's calculations based on data from INEGI.

\subsection{Economic space and economic territory}

The economic structure of Sonora is observed through its production activities, which is characterized by the predominance of tertiary and secondary economic activities with $52.3 \%$ and $40.5 \%$ respectively, of the total states GDP, whereas the contribution of the primary sector is only $7.2 \%$, which is integrated by agriculture, livestock, fishing and hunting. It is also highlighted the importance of the industrial activities due to their high share, compared to the nations, which on average is $35 \%$ of the total GDP ${ }^{12}$. Furthermore, its main industrial base is related to manufacturing industries, which accounts for half of total industrial production, in which manufacturing of the transport equipment accounts

\footnotetext{
${ }^{12}$ Own estimations based on Table 1.1 gross domestic product by economic sector of economic activity 2008-2012. INEGI. Anuario estadístico y Geografía de Sonora 2014 and also INEGI. México en cifras.
} 
for $53 \%$ of the total value of the manufacture industry, followed by computing equipment and electronic components $(26 \%)$ and food manufacture $(21 \%)$. The other industrial activities, according to their economic importance are construction $(25 \%)$, mining $(17.0 \%)$ and electricity and water supply (8.2\%). Finally, the service sector is notorious for its share $(32.1 \%)$ while commerce and transport accounts for $20.1 \%$.

It is remarkable that Sonora is important at the national level for its economic specialization in the primary sector, especially in agriculture, animal breeding and fisheries, despite that its main regional economic activities are industrial: Manufacture, construction, electricity production, health and government services.

Furthermore, the spatial distribution of the economic activity is not homogeneous, given that only nine nodes account for almost all of the total value $\operatorname{added}^{13}$ (94.6\% of employment and $81.2 \%$ of population). See the table below.

The economic importance of these nodes is complemented with their specialization and economic diversification. However, the specialization of each node shows a very different spatial pattern, compared to the region as a whole. Despite Sonoras specialization in agriculture at the national level, only Caborca and Obregon City are involved in this activity ${ }^{14}$. Animal breeding is located only in Obregon City and fisheries only in Guaymas-Empalme, Puerto Peñasco and San Luis Rio Colorado, as shown in Table.

\footnotetext{
${ }^{13}$ It is worth commenting that the identification of economic nodes within Sonora was performed by analyzing at a local level, the weight and importance of the sector's value added, as well as its share of value added, employment and population. Moreover, the nodes that we are consider accounts for the $79 \%$ of total population, $81 \%$ of employment and about $95 \%$ of value added. Furthermore, it is necessary to clarify that economic participation was obtained from the data differences between locality and municipality to whom it belongs. The results shows the important share of locality, which values fluctuate around the $98.5 \%$ of municipal value added, $92.7 \%$ in employment municipality and $92.3 \%$ in population density of the municipality. In fact this analysis is based on the Pareto principle (80-20) in which $80 \%$ of the production typically takes place in $20 \%$ of the economic activity. The Pareto Principle or 80-20 rule observes that most things have an unequal distribution. This means that for many events roughly $80 \%$ of the effects come from $20 \%$ of the causes Of course, this ratio can change and it could be $90 / 10$ or $90 / 20$, etc. In terms of a set of data, the ratio means that the distribution of the data is characterized by the existence of a typical existent value, to which the distribution of data is centered. Therefore, generally followed is a cumulative distribution of the value of the data according to the laws of power.

${ }^{14}$ The agriculture specialization is interpreted by the economic specialization of the nodes in the subsector, named: Services related to agricultural and forestry activities, due to the lack of data of the primary sector.
} 
Table 1. Economically dominant nodes, 2008(\%)

\begin{tabular}{|l|r|r|r|}
\hline Nodo (locality) & \multicolumn{1}{|c|}{$\begin{array}{c}\text { Total } \\
\text { Population }\end{array}$} & $\begin{array}{c}\text { Employme } \\
\text { nt }\end{array}$ & \multicolumn{2}{c|}{$\begin{array}{c}\text { Value } \\
\text { Added }\end{array}$} \\
\hline Hermosillo & 30.7 & 32.5 & 52.1 \\
\hline Obregón City & 12.8 & 13.3 & 12.0 \\
\hline Nogales & 9.1 & 9.3 & 10.0 \\
\hline $\begin{array}{l}\text { Guaymas- } \\
\text { Empalme }\end{array}$ & 6.7 & 6.6 & 8.2 \\
\hline Caborca & 2.6 & 2.6 & 3.4 \\
\hline Navojoa & 4.9 & 4.7 & 3.0 \\
\hline $\begin{array}{l}\text { San Luis Río } \\
\text { Colorado }\end{array}$ & 6.8 & 6.6 & 2.7 \\
\hline Agua Prieta & 3.3 & 3.3 & 1.7 \\
\hline Puerto Peñasco & 2.4 & 2.4 & 1.4 \\
\hline Total Nodes & $\mathbf{7 9 . 4}$ & $\mathbf{8 1 . 2}$ & $\mathbf{9 4 . 6}$ \\
\hline
\end{tabular}

Source: Author's calculations based on data from INEGI.

This table shows that industry is the most important sector of economic activity in Sonora, but only seven out of nine nodes specialize in this. It can also be observed that there is an important industrial differentiation per node. Hermosillo is the main industrial center, specializing in five activities; whereas Obregon specializes in four. However, both of these cities differ in their industrial basis. On the one hand, Hermosillo is more diversified, with emphasis in basic industry, basic metal industry, manufacture of transport equipment, manufacture of metal products and manufacture of non-metal products. On the other hand, Obregon City specializes in food, beverages and tobacco production, as well as in basic metal production. Notwithstanding, it is important to highlight that there is also an industrial differentiation in the other four industrial nodes: Guaymas-Empalme, Navojoa, Agua Prieta and Nogales. San Luis Rio Colorado only specializes in one industrial sector.

When it comes to services and commercial activities, the nodes are also remarkable for their differences. The nodes along the border are related to cultural, recreational activities and retail. On the contrary, the nodes in the central and southern areas specialize in wholesale and have a different pattern of economic 
specialization in services. Obregon City and San Luis Rio Colorado are more diversified than Hermosillo, which contradicts Hermosillo's important participation in the regional economy and population, which by the way, it also specializes in mass media information and social services.

Table 2. Economic specializationby main nodes of the Sub regions

\begin{tabular}{|c|c|c|c|c|c|c|c|c|c|c|}
\hline & $\operatorname{sectar}$ & Aga Prikb & Cabae & Obregin $\mathrm{Ch}$. & Guagmas-Empalme & e Bermosilt & Favoja & Ilogeles & Puer b Perias seo & San Luis Rio Colbra do \\
\hline 112 & Anima breesing and production & 0000 & 0.07 & 3.31 & 0.10 & 0.99 & 0.01 & 0,00 & 005 & 0.00 \\
\hline 114 & Fshing huning and tapping & 000 & 0.50 & 0.11 & 8.18 & 0.08 & 0.1 & 0,00 & 110 & 420 \\
\hline 115 & Seviose re alded to agriculual and bresty actives & 0000 & 9.5 & 5.90 & 0.07 & 0.39 & 0.55 & 000 & 000 & 000 \\
\hline $21-23$ & Basic Industy & 0.39 & 280 & $2 \pi$ & 0.23 & 124 & 0.85 & Q.11 & 0270 & 0.37 \\
\hline & 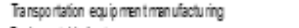 & 165 & 000 & 0.20 & 286 & 18 & 0.22 & 0.39 & 001 & 0.28 \\
\hline 331 & Basicmeal intusty & 000 & 0.05 & $2 \pi$ & 000 & 113 & 0,00 & 000 & 000 & 000 \\
\hline 311 & Food industy & 018 & 0.8 & 238 & 122 & Q.78 & 185 & 005 & 049 & 0.95 \\
\hline 312 & Beverge and tobacos ind usties & 0.14 & 365 & 100 & 0.04 & 0.59 & 618 & 0.14 & 0.10 & 0.08 \\
\hline 334 & 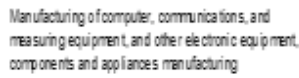 & 132 & 000 & 0,00 & 0.8 & 0.29 & 0.63 & 7.8 & 000 & 457 \\
\hline 332 & Netal product menufactung & 012 & 0.03 & 18 & 0.27 & 110 & 005 & 228 & 009 & 0.09 \\
\hline 327 & Nonméal licmineral productsmenuácturing & 0.54 & 0.08 & 0.3 & 0.35 & 153 & 0.8 & 0.22 & 0.94 & 0065 \\
\hline 339 & Oher menứacturing industives & 296 & 0.02 & 0.08 & 286 & 0.05 & 0.31 & 7.82 & 0.10 & 0.23 \\
\hline 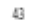 & Wholesale trade & 114 & 0.96 & 0.93 & 117 & 103 & 120 & 0.05 & 071 & 102 \\
\hline 46 & Real tade & 178 & 123 & 133 & 0.93 & 073 & 130 & 100 & 322 & 238 \\
\hline 180 & Tarsportation,postal sevices and warehousing & 061 & 0.54 & $1 \pi$ & 0.65 & 0.90 & 0.80 & 152 & 018 & 0.4 \\
\hline 51 & Nass media infomriton & 114 & 0.24 & 0.3 & 0.5 & 156 & 0.23 & 0.17 & 050 & 0.57 \\
\hline 52 & Francial and insurnoe servicas & 399 & 0.06 & 187 & 0.61 & 0.66 & 101 & 0.82 & 324 & $2 \pi$ \\
\hline 5256 & Utan Seviogs & 020 & 0.20 & 108 & 0.38 & 0.94 & 0.93 & 222 & 162 & 0.91 \\
\hline $61-62$ & Social Sevioes & 130 & 0.58 & 107 & Qn2 & 105 & 0.67 & 0.95 & 060 & 195 \\
\hline $71-72$ & Oud tral and receatie sevices & 185 & 0.37 & 184 & 0.83 & 0.05 & 0.98 & 107 & 465 & 251 \\
\hline 81 & Other sevices (except gove mment activies) & 127 & 0.05 & 215 & Q.4 & 0.81 & 0.73 & 0.82 & 141 & 197 \\
\hline
\end{tabular}

Source: Author's calculations based on data from INEGI.

3. The identification of the spatial economic functional units (SEFU) and of the economic sub-regions

The identification and delimitation of the spatial economic functional units are based on the identification of the economic and population nodes (already done in the first step). Then, it was necessary to identify and select the node's area of influence. This can be done relying on the assumption that an economic node is also the economic center of a market area, whose periphery or area of influence depends on physical proximity or distance, and on the economic attraction that the node exerts over it.

It is important to recall that these economic spatial units lead us to identify the economic space, in which the economic activity takes place. Of course, there is no coincidence with political or geographical units. According to our interpretation, their delineation is absolutely essential, in order to understand the economic behavior in space. We delimitate these units using the Reilly Index ${ }^{15}$, which essentially, measures the economic distance between a pair of nodes and their possible area of influence, based on the assumption that a pair of nodes

\footnotetext{
${ }^{15}$ The Reilly Index measures inverse relationship between size and distance between a pair of sites, denote as: $\mathrm{BP}=(\mathrm{Pa}+\mathrm{Pb}) / \sqrt{\left(D a+D b^{\prime}\right)}, \mathrm{BP}=$ Border point, $\mathrm{Pa}=$ Population site a, $\mathrm{Pb}=$ Population site $\mathrm{b}, \mathrm{Da}=$ Distance to the site, and $\mathrm{Db}=$ Distance to the site $\mathrm{b}$. Thus, the size and distance of the nodes is taken into account.
} 
that are spatially located near each other may be in competition for the attraction of the nearby areas of influence, then it is draw their borders in order to establish who is attracting those areas.

According to the results of the index, nine spatial economic functional units were identified. However, in order to integrate all economic areas that form the region, another SEFU, characterized by the extreme dispersion of their localities was also identified. Consequently, the economic space of Sonora is structured by ten SEFU's, Therefore, the most important economic characteristics of the economic sub-regions of Sonora reflect a great heterogeneity, given that only four of its sub-regions account for almost the total production of the region. The economic sub-regions Hermosillo, Agua Prieta, Obregon and Nogales account for $83 \%$ of the regional production, $80 \%$ of the total value added and $72 \%$ of total regional employment. At the same time, as a whole they account for $65 \%$ of total population of the region. The other six economic sub regions share $17 \%$ of the regional production, $20 \%$ of the total value added and $28 \%$ of the employment, with only $35 \%$ of the total population of the region. (See Map 3 and Table 3 below.)

Map 3

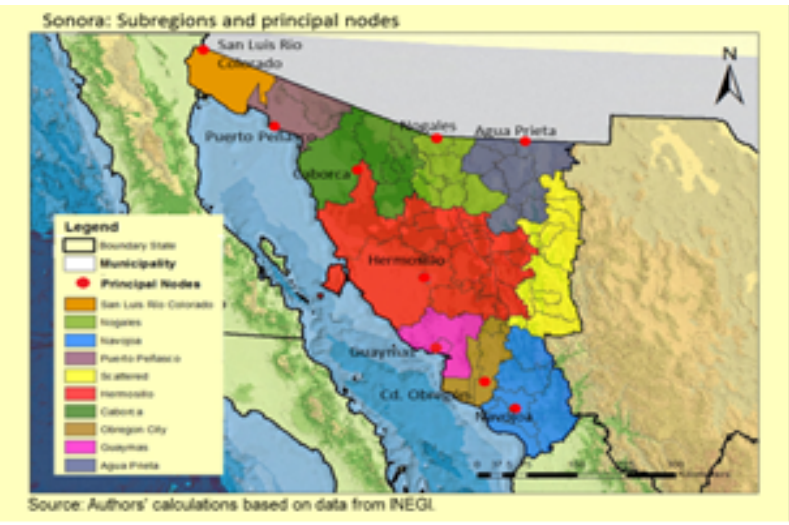

Source: Author's calculations based on data from INEGI. 
Table 3: Economic Share by sub-region, 2008 (\%)

\begin{tabular}{|l|r|r|r|r|}
\hline \multicolumn{1}{|c|}{ Sub-region } & Employment & \multicolumn{1}{|c|}{$\begin{array}{c}\text { Total Gross } \\
\text { Output }\end{array}$} & \multicolumn{1}{c|}{$\begin{array}{c}\text { Value } \\
\text { Added }\end{array}$} & \multicolumn{1}{c|}{$\begin{array}{c}\text { Total } \\
\text { Population }\end{array}$} \\
\hline Hermosillo & 35.65 & 49.82 & 43.31 & 31.89 \\
\hline Agua Prieta & 4.93 & 16.13 & 16.14 & 5.65 \\
\hline Obregon City & 17.18 & 10.76 & 10.88 & 16.95 \\
\hline Nogales & 14.22 & 6.05 & 8.91 & 10.58 \\
\hline Guaymas & 7.91 & 4.52 & 6.67 & 7.67 \\
\hline Navojoa & 8.80 & 6.51 & 6.18 & 13.46 \\
\hline Caborca & 2.98 & 2.23 & 3.26 & 3.63 \\
\hline San Luis Rio & 5.13 & 2.19 & 2.27 & 6.64 \\
Colorado & 2.89 & 1.16 & 1.41 & 2.60 \\
\hline Sonoita-Peñasco & 0.29 & 0.63 & 0.97 & 0.93 \\
\hline Scattered & $\mathbf{1 0 0 . 0 0}$ & $\mathbf{1 0 0 . 0 0}$ & $\mathbf{1 0 0 . 0 0}$ & $\mathbf{1 0 0 . 0 0}$ \\
\hline Total & & & &
\end{tabular}

*Scattered refers to localities, that have a very disperse location pattern.

Source: Authors' calculations based on data from INEGI.

\section{The construction of the regional bottom-up input-output ma- trix of Sonora}

The methodology for the construction of the regional matrix of Sonora from the bottom up approach, comprises the following steps: 1 . The identification of the dominant economic sectors by economic sub region, applying the Pareto distribution criteria; 2 . The estimation of the economic specialization index by economic sub region ; 3 . The built of the sub regional input-output tables, which is done firstly through an adjustment to the Fleggs methodology, firstly by taking into account the economic specialization coefficient of the sub regions, secondly by estimating lambda $\lambda$, as a definition of the economic size of the sub region compare to regional and national production by applying the following index:

$$
\lambda_{r}^{*}=\log _{2}\left[\left(\frac{1+Y_{s r i}}{Y_{r}} \frac{1+Y_{r}}{Y_{n}}\right]^{\delta}\right.
$$


Where:

$Y_{s r}=T G P$ Sub-regional

$Y_{r}=T G P$ Regional

$Y_{n}=T G P$ National

Then, the input-output table by economic sub region is calculated, by multiplying the economic specialization coefficient by economic sub region, using the technical coefficient of state production and the gross production of the economic sub region, which is specified as:

$$
F L Q_{\text {Subrij }}=\left(C I L Q_{\text {Subrij }}\right)\left(\lambda_{S u b r}^{\delta}\right)\left(a_{i j}\right)
$$

Where:

$F L Q_{i j}$, is the modified Flegg's coefficient;

$C I L Q_{i j}$, is the crossed-holding location coefficient;

$\lambda$, is an algorithm that takes into account the economic size of the sub-region; $a_{i j}$, represents the national technical coefficients.

According to Davila 2002, the value of $\lambda^{\delta}$ increases as the size of the region those it. Then, the greater the value of lambda, the lower the value of the regional adjustment of imports and consequently, the higher the level of regional selfsufficiency. Flegg and Webber have found, through various studies in England, that a value of $\delta=0.3$ can minimize the differences between the multipliers obtained by location coefficients and those calculated by direct observation.

Therefore, following Fleggs proposition, it is estimated the percentage of the technical coefficients of production supplied within the region, based on the interpretation of the modified location coefficient, as follows:

$$
\begin{gathered}
F L Q_{i j} \geq 1 \therefore t_{i j} \equiv 1 \\
F Q L_{i j} \leq 1 \therefore t_{i j}=F Q L_{i j}
\end{gathered}
$$

Nevertheless, given that Fleggs proposition does not have any proposal for the inter regional trade coefficients analysis, we first identified the sub regions commercial function as buyer or seller, based on those performances at sectorial level in the nation, through the analysis of the national input-output tables. Thus, we identified the sectors of the sub regions, which belong to horizontal or vertical vectors in the regional matrix, taking as a reference the national commercial function that the sector plays as buyer or seller. Consequently, these sectors were located in the sub regions through census data, allowing their classification of the sub regions as sellers and buyers.

Given the lack of inter-sub regional trade information and to the great amount of technics for their estimation (Miller and Blair, 2009, Chapter 8, we made a preliminary estimation of sales and purchases between sub regions, taking into account their differences in economic specialization and the value of economic interaction among them, that we estimated through the application 
of an economic interaction index. (Attachment III). Finally, we estimated the multiple sub regional matrix of Sonora, created by the distribution of the gross production value, that include the trade coefficients of the sub regions by the adjustment to Fleggs methodology and also the ones that come about from the application of the RAS method to the values of the economic interactions index among sub regions. ((Attachment IV).

5. The comparative analysis of the regional economic linkages and their multiplier effects between the top-down and bottom-up approaches.

As we mentioned before, in this step we applied both a spatial and a sectorial analyses of the economic linkages and the multiplier effects, derived from the regional matrices constructed by both approaches.

\subsection{The spatial analysis}

In this first part we used the basic approach of Watanabe and Chenery (1958) to analyze the economic linkages ${ }^{16}$ and their location in space, using the inverse input-output matrix (Leontief matrix) which is denoted as $r_{i j}$, where $\mathrm{i}$ is the seller, and $\mathrm{j}$, the buyer. Thus, we classify them according to their forward and backward linkages. The total effects of forward interdependence can be interpreted as follows:

$$
R_{j}=\sum_{i=1}^{n} r_{i j}
$$

This represents the impact of an increase in sector $\mathrm{j}$ derived from a unit increment in the final demand of sector $i$. The effects of complete forward interdependence, on the other hand, are interpreted as the increase in sector i derived from a unit increase of the final demand of sector $\mathrm{j}$. This is considered a measure of the degree of forward linkage of sector $\mathrm{j}$ and it is represented by the following:

$$
R_{i}=\sum_{j=1}^{i} r_{i j}
$$

The traditional classification of chains (Chenery and Watanabe, 1958) can be classified as follows:

- Base sectors that refer to economic activities with high forward linkages and low backward linkages

\footnotetext{
${ }^{16}$ The determination of the impacts generated by the sectorial and spatial interactions of an economy is crucial for economic analysis and for the implementation of an effective public policy tool. The chains of production activities and their backward and forward links reflect the economic relationships and productive dependence in a regional structure, in which these chains are based on specialized sectors. The backward link of the chains reflects the dependence of economic activity on inputs that could have been provided by other region; whereas the forward link of the chains reflects the specialized supply of inputs from one sector of a region to other economic activities of another region. To evaluate these chains, the rate of direct linkages was used back and forth, where the type of chain determines the role of the sectors in the economy
} 
- Key sectors that refer to economic activities with strong linkages forward and backward

- Sectors of strong drag that refer to activities with low forward linkages and high backward linkages

- Independent sectors that consist of activities with low linkages backward and forward

The classification of the sectors is determined by the existence or nonexistence, of forward or backward linkages. For this, we calculated the following relations: ${ }^{17}$

$$
\mu_{i}=\frac{\sum_{i} Z_{i j}}{Z_{j}}
$$

Where:

$Z_{j}=$ Production of branch $\mathrm{j}$

$Z_{i j}=$ Uses of branch $\mathrm{j}$ of inputs of branch $\mathrm{i}$

Therefore, according to the associations between and, we have the following classification:
$\omega_{i}>\bar{\omega}_{j}$
$\omega_{j}<\bar{\omega}_{j}$
$\mu_{i}<\bar{\mu}_{i}$
Base sectors
Key sectors
$\mu_{j}>\bar{\mu}_{j}$
Independent sector
Drag sectors

\footnotetext{
${ }^{17}$ In this study, once and had been calculated, the results were standardized in order to be able to graph them in a scale from 0 to 2
} 


\subsubsection{The economic linkages of the regional matrix using the top- down approach}

The economic linkages of this approach, despite the industrial importance of the region, (as observed in Attachment 1, Table 4 and Graph $1^{18}$ ), show that only the manufacturing sectors 334 and 336 are considered as key sectors. The first one includes the manufacturing of computers, communication devices, measuring equipment, components and appliances, and other electronic equipment, whereas the second is composed of manufacturing of transportation equipment. It is remarkable that both of these have an important presence at the national level.

However, astonishingly, food Industry (311) and basic industry (2), are classified only as drag sectors, which means they do not have forward sectorial linkages, even though the existence of an important food processing industry, such as fishing industry, animal breeding and meat processing. The analysis also ignores the industrialization of the agriculture production and the usual linkages and indivisibilities that should exist among the subsectors of the basic industry, such as construction, mining and electricity generation.

Furthermore, this is not only a matter of sectorial linkages as such, but also of the peculiarities of the economic structure and specialization at intra-regional level. (See paragraph 2.3 and Table 2).

These reveal important omissions in the regional industrial economic linkages, clearly observed at the sub regional level, as it is the case in the economic sub regions of Obregon City and Guaymas, which show their economic specialization in animal breeding and production and services linked to the agriculture production and the specialization of food industry, while Guaymas presents a similar pattern between fishing activities and food industry. (See Table 2)

Hermosillos sub region shows a very similar pattern in the case of the relationships between economic specialization in basic industry (2) and in the metal products, manufacturing (332), non-metallic minerals manufacturing (327) and the transport equipment manufacturing (336). It is obvious, that this methodology can only identify industrial sectorial linkages, without any consideration to their location in the sub regions and in the region as a whole. To some extent, in this aggregate analysis, the region does not show the differences between the location of industrial production and consumption sites, emulating a national analysis.

\footnotetext{
${ }^{18}$ In order to facilitate the analysis of the results of the sectors' economic linkages, we use a Cartesian graph to show the data recorded according to the Chenery and Watanabe indexes. Thus, the forward economic linkages are plotted in the x-axis, which is an indicator of the demand for all branches of a particular branch while in the y- axis the backward economic linkages are plotted indicating the effects of demand of a branch for their suppliers. Thus, the value of the scale on both axes goes from 0 to 2 , which results in the formation of four quadrants. In the first one, in the y axis we plot the values of the base sectors that range from 1 to 2 ; in the second quadrant, of the same axis, key sectors with values from 1 to 2 are located; in the third quadrant, which runs from 0 to 1 , the independent sectors are recorded; and finally in the fourth quadrant that runs from 0 to 1 , we locate the drag sectors.
} 
The same thing applies to services, mainly in the case of Transportation (4849) and urban services (53-56), which are classified as drag sectors, with high backward economic linkages, questioning the essential function of the transport sector as connector of production and consumption, as well as the basic origin or urban services as essential basis infrastructural facilities, upon which other economic activities come about. Thus it is obvious the key sector character of the transportation activities and the forward economic linkages of the urban services.

According to this methodology, the regional economy of Sonora is distinguished mainly by its major sectorial dispersion and lack of integration, which contrasts with the real regional data at the sub regional level. It reveals only sectorial linkages, without taking into account their location on the sub-economic regions. Evidently, if we use this analysis to design policies for regional and territorial economic development, a misleading vision of the behavior of the economic region and their economic linkages will be showed.

The construction of a regional matrix without sub-regions seems to contradict the economic spatial specialization and the association between economic sectors, according to the spatial distribution of economic activities and the development of economic sub-regions and territories.

Furthermore, the economic linkages showed by this methodology, seems to distort the modelling of the regional economy, due to the sectorial and aggregated bias of the region. Therefore, we conclude that the construction of a regional I-O matrix using a top-down approach, without space and sub regions, is insufficient for the comprehension of the regional economic structure and for policy making and decisions for economic growth and development.

5.1.2 The linkages of the regional matrix using the bottom-up approach

We constructed the bottom-up regional matrix of Sonora using the location of the economic activity and population, in order to reveal its spatial and territorial structure, which enabled us to characterize the economic region integrated by ten economic sub-regions. According to this approach, the economic linkages of the region are quite different when compared to those resulted from the top-down approach, due to its classification of the industrial and services economic linkages. The bottom-up approach shows that five economic sectors are classified as key sectors: basic industry (2); food industry (311), manufacturing of computers, communication devices, Measuring Equipment, other electronic equipment; Components and appliances manufacturing (334), transportation equipment manufacturing (336), transportation, postal and warehousing services (48-49). (See Table 5 and Graph 2)

These results are coherent with the existence of the main economic specialization and diversification of the economic structure of the identified economic sub regions of Sonora. These are Animal Breeding, Food industry, Transport equipment manufacturing, Metal products manufacturing, Basic metal industry, Services related to agriculture, and Manufactures of the assembly industry 
(See Table 2). Therefore, this reveals the basic economic sectors of the regional economic structure as identified from the regional analysis at sub regional level.

Finally, the sectors that are classified as forward linkages are commercial activities (43-46) and urban services (53-56) and the no metallic mining sector is characterized as having a backward linkage. The rest of the 12 sectors are classified as independent sectors which means to some extent, a sort of sectorial autarky.

5.2 The identification of regional clusters, economic linkages and their multiplier effects

The methodology for this analysis is the principal component analysis (Fester Bergman, 2000) for cluster analysis. However, we made some statistical adjustments in order to find the existence of clusters and their linkages and economic performance. They rely on bottom-up and top-down regional matrices ${ }^{19}$.

5.2.1 The parts of the analysis and their interpretation and application

In order to make a synthetic and easier interpretation of our analysis and its results, we divided it into three cases:

1. We denote this part as A, and it is related to the existence of economic sectors within a cluster is the first element of our analysis and it is derived from the construction of a correlation matrix, followed by a principal component analysis. From this analysis we get the identification of clusters and their economic component sectors.

2. The linkages of identified clusters with the individual economic sectors are observed through the combined analysis of the circle of correlations and of the individual coordinates of these sectors. From this analysis we obtain the linkages of the cluster and its sectors. This second part of the analysis is denoted as B.

3. The economic performance of the clusters is analyzed through the analysis of multipliers that measure the impact of the sectorial linkages of production clusters and those coming from an increase in demand. From this analysis we obtain the estimation of the effects on the behavior of the production and the demand caused by the economic links of the productive sectors of the clusters. This third part of the analysis is denoted as C.

Nevertheless, the interpretation of this analysis requires a comprehensive view of the different parts, in order to know the relationships among them and the results they produce, as well as the conclusions. For that purpose we identified three possible outcomes:

Case I. If the sectors that make up the cluster (A) are those that establish economic links (B), then the multiplier effects reflect adequately the impacts of the production and demand multipliers analyzed. (C)

${ }^{19}$ The basic details of the methodology can be found in the Attachment IV 
If this is the case, then the three parts of the analysis are logically equivalent $(\mathrm{A} \equiv \mathrm{B} \equiv \mathrm{C})$, which implies that the information provided by the construction method of the corresponding regional matrix is statistically consistent with the economic structure and economic interdependencies of the presented economic sectors given that they include linkages of economic sectors which are statistically relevant in the cluster.

Case II. If the sectors in the cluster (A) are smaller than those that establish economic linkages (B), then the multiplier effects do not adequately reflect the impacts of the production and demand multipliers analyzed, since they are overestimated $(\mathrm{C})$.

If this is the case, then the three parts of the analysis are not logically equivalent $(\mathrm{A} \not \equiv \mathrm{B} \not \equiv \mathrm{C})$, due to $\mathrm{A}>\mathrm{B}$ which implies that the information provided by the method of construction of the corresponding regional matrix is not statistically consistent with the economic structure and economic interdependencies of the economic sectors that it presents, since they do not include the linkages of economic sectors which are statistically relevant in the cluster.

Case III. If the sectors in group (A) are bigger than those that establish economic linkages (B), then the multiplier effects do not adequately reflect the impacts of the production and demand multipliers analyzed, since they are underestimated $(\mathrm{C})$.

If this is the case, then the three parts of the analysis are not logically equivalent $(\mathrm{A} \not \equiv \mathrm{B} \not \equiv \mathrm{C}), \mathrm{B}>\mathrm{A}$, which implies that the information provided by the method of construction of the corresponding regional matrix is not statistically consistent with the economic structure and economic interdependencies of the economic sectors that it presents, given that they include linkages of economic sectors which are not statistically relevant in the cluster.

\subsubsection{The results of the analysis}

The principal components analysis was applied in order to identify the integration of the representative clusters of the majority of economic sectors for both regional matrixes. For this purpose, the first two main components were selected, that shown their association by linear combinations of the economic sectors. These components presents the maximum variability of the data of those sectors, which represent $60 \%$ of the total in both matrices as can be seen in their accumulated share of both components in the matrices in Table 4. However, it is worth mentioning that the number of principal components extracted of an analysis can be equal to the number of observed variables. Even so, in most analyzes, only the first few components have meaningful amounts of variance. 
160 Nueva Época REMEF (The Mexican Journal of Economics and Finance)

20 Thus, we assume that the contribution to the variance of the analysis of the data of the remaining components, is not representative according the purposes of our research.

On the other hand, the most relevant sectors of each component, which represent $80 \%$ of the total eigenvalues, allowed us to identify the most relevant sectors of each component or cluster of both analyzed matrices. Hence, as it is displayed in the following table of components of the regionalized matrices in the top-down matrix, 13 productive sectors were identified for the first cluster and 14 for the second cluster.

In addition, according to their eigenvalues, in the first cluster in order of importance the following sectors stand out: trade (43-46); transport, (48-49); manufacturing of transport equipment, (336) and urban services (53-56), meanwhile in the second cluster are beverages and tobacco (312) and Basic metal industry (331).

In the case of the bottom-up regional matrix, the two principal components share $59.1 \%$ of the data; we also identified the economic sectors that integrate their clusters, given their $80 \%$ of accumulated share of eigen values. Besides, the first cluster has 17 sectors and the second one, 16. Regarding the type of economic sectors in the clusters, in the first cluster, in decreasing order the following economic sectors appear: Social services, (6); Food Industry (311); Other Manufacturing Industries, (339) and Transport services (53-56) whereas in the second cluster we have Manufacturing of transportation equipment, (336); Financial and insurances services, (52); Metal Products manufacturing, (332); and Animal breeding and their production (112).

${ }^{20}$ See: Principal Component analysis http://support.sas.com/publishing/pubcat/chaps/55129.pdf 
Table 4

\begin{tabular}{|c|c|c|c|c|c|c|c|c|c|c|c|}
\hline & & & СОMPO & VENTS $O$ & F THE & EGION & LIZED & MATR & & & \\
\hline & & DP-DOV & N MATR & & & & & рттом & $-U P M A$ & $R I X$ & \\
\hline & $\overline{\text { mpone }}$ & $\overline{\text { it } 1}$ & & mponen & & Con & ponen & & & mponen & \\
\hline & $\begin{array}{c}\text { SD: } 2.8 \\
\text { V: } 0.3 \\
A S: 0.3\end{array}$ & & & $\begin{array}{c}S D: 1.95 \\
V: 0.19 \\
A S: 0.61\end{array}$ & & & $\begin{array}{l}2.79 \\
0.391 \\
S: 0.39\end{array}$ & & & $\begin{array}{l}D: 2.002 \\
V: 0.201 \\
A S: 0.59\end{array}$ & \\
\hline$s$ & $w$ & $S h$ & $s$ & $w$ & $S h$ & $S$ & $w$ & $S h$ & $s$ & $w$ & $S h$ \\
\hline 43-46 & 0.312 & $8 \%$ & 312 & 0.327 & $8 \%$ & 6 & 0.33 & $3 \%$ & 336 & 0.471 & $12 \%$ \\
\hline 48-49 & 0.307 & $15 \%$ & 331 & 0.300 & $15 \%$ & 311 & 0.32 & $5 \%$ & 52 & 0.445 & $13 \%$ \\
\hline 336 & 0.306 & $22 \%$ & 114 & 0.298 & $22 \%$ & 339 & 0.31 & $9 \%$ & 332 & 0.411 & $15 \%$ \\
\hline 53-56 & 0.301 & $30 \%$ & 7 & 0.296 & $29 \%$ & 53-56 & 0.3 & $12 \%$ & 112 & 0.359 & $27 \%$ \\
\hline 112 & 0.294 & $37 \%$ & 52 & 0.283 & $36 \%$ & 51 & 0.3 & $20 \%$ & 2 & 0.357 & $28 \%$ \\
\hline 8 & 0.29 & $44 \%$ & 115 & 0.263 & $42 \%$ & 8 & 0.28 & $26 \%$ & 7 & 0.326 & $29 \%$ \\
\hline 311 & 0.281 & $51 \%$ & 6 & 0.248 & $48 \%$ & 334 & 0.25 & $31 \%$ & 327 & 0.133 & $34 \%$ \\
\hline 332 & 0.256 & $57 \%$ & 311 & 0.246 & $53 \%$ & 331 & 0.25 & $37 \%$ & $53-56$ & 0.108 & $34 \%$ \\
\hline 61-62 & 0.244 & $63 \%$ & 53-56 & 0.233 & $59 \%$ & 312 & 0.24 & $41 \%$ & 8 & 0.074 & $48 \%$ \\
\hline 312 & 0.216 & $68 \%$ & 112 & 0.231 & $64 \%$ & 327 & 0.21 & $47 \%$ & 334 & 0.067 & $50 \%$ \\
\hline 52 & 0.209 & $73 \%$ & $43-46$ & 0.198 & $69 \%$ & $48-49$ & 0.2 & $49 \%$ & 115 & 0.066 & $66 \%$ \\
\hline 327 & 0.204 & $78 \%$ & 332 & 0.191 & $74 \%$ & 7 & 0.2 & $56 \%$ & 311 & 0.043 & $66 \%$ \\
\hline 51 & 0.162 & $82 \%$ & 327 & 0.188 & $78 \%$ & 332 & 0.17 & $59 \%$ & 312 & 0.035 & $66 \%$ \\
\hline & & & $48-49$ & 0.183 & 0.82 & 115 & 0.16 & $64 \%$ & $48-49$ & 0.027 & $67 \%$ \\
\hline & & & & & & 2 & 0.15 & $71 \%$ & 6 & 0.022 & $67 \%$ \\
\hline & & & & & & 112 & 0.12 & $73 \%$ & 51 & 0.013 & $82 \%$ \\
\hline & & & & & & 52 & 0.11 & $81 \%$ & & & \\
\hline $\begin{array}{l}\text { SD: Sta } \\
\text { V: Varia } \\
\text { AS: Acc }\end{array}$ & $\begin{array}{l}\text { ndar De } \\
\text { ance } \\
\text { umulate }\end{array}$ & $\begin{array}{l}\text { iation } \\
\text { d Share }\end{array}$ & $\begin{array}{l}\text { S: Sectc } \\
\text { Sh: Sha } \\
\text { W:Weig }\end{array}$ & & & & & & & & \\
\hline
\end{tabular}


The combined analysis of the circle of correlations and the coordinates of individuals allowed us to establish relationships between sectors and clusters through the location of sectors in the coordinates of individuals and their location with respect to the circle of correlation, which indicates their relationship between the sectors considering if they belong or not to the clusters. In this sense, the economic linkages of the sectors are identified, as well as their adherence to any of the clusters. Thus, sectors that do not belong to the clusters but have linkages are also identified. These results of our model of cluster analysis and interpretation three parts: (A) Integration of economic sectors to a cluster; (B) Linkage of economic sectors belonging to a cluster and (C) performance of economic sectors of a clusters. The result of its application can give rise to three cases:

1. $(\mathrm{A} \equiv \mathrm{B} \equiv \mathrm{C})$, Statistical Coherence in the regional matrix constructed: Representaive Multiplier effects.

2. $(\mathrm{A} \not \equiv \mathrm{B} \not \equiv \mathrm{C})$, due to $\mathrm{A}>\mathrm{B}$. No Statistical Coherence in the regional matrix constructed: Underestimation of the Multiplier effects.

3. $(\mathrm{A} \not \equiv \mathrm{B} \not \equiv \mathrm{C})$, No Statistical Coherence in the regional matrix constructed: Overestimation of the Multiplier effects.

The multiplier effects are quantified with the production multiplier and its induced effects in the production sectors. Therefore, if there is no proportionality between identified sectors of the cluster and if there are linkages that do not belong to the cluster or there are a lack of them, the estimates of the multipliers will be inadequate as already mentioned.

The result of this analysis shows that in the clusters of the top-down matrix, there are identified productive sectors that without belonging to the clusters have linkages with some of its economic sectors. This is the case in both clusters (see table 5). In cluster 1 , the economic sectors that have economic linkages with its sectors, are Fishing and Hunting, (114); Computer and other electronic equipment, (334), and cultural and recreational services (7). In the second cluster, on the other hand, we have Computer and other electronic equipment, (334); Manufacturing and transport Equipment; (336); other manufacturing industries, (339); Mass Media, (51) and other services (8). With respect to the bottom-up matrix, clusters 1 and 2 are have chained sectors that correspond to those of the cluster so, the multiplier effects are representative of the clusters and therefore this matrix is statistically consistent with the economic structure and interdependencies determined by the bottom-up methodology (see table 6)

Hence, these results show that the top - down matrix is not statistically consistent with the economic structure and interdependence of economic sectors derived from this approach, which shows the importance and transcendence of spatial analysis of the economy. 
Table 5

\begin{tabular}{|c|c|c|c|c|c|c|c|}
\hline \multicolumn{8}{|c|}{ Linkages and Muktipliers of the first cluster } \\
\hline \multicolumn{8}{|c|}{ TOP-DOWN MATRXX } \\
\hline Belongs & $o_{f}^{a}$ & $T_{j}^{a}$ & Linkages & Does not belongs & $\boldsymbol{o}_{j}^{a}$ & $\boldsymbol{T}_{j}^{a}$ & Linkages Type \\
\hline $43-46^{2}$ & 1.15 & 1.45 & D & $114^{*}$ & 1.07 & 1.01 & $\mathrm{I}$ \\
\hline $48-49^{*}$ & 1.19 & 1.15 & D & 115 & 1.10 & 1.01 & I \\
\hline $336^{*}$ & 1.11 & 2.18 & $\mathrm{~K}$ & $21-23$ & 1.23 & 1.14 & D \\
\hline $53-56^{*}$ & 1.07 & 1.21 & I & 331 & 1.32 & 1.18 & B \\
\hline $112^{*}$ & 1.22 & 1.05 & I & $334^{*}$ & 1.37 & 1.50 & $\mathrm{~K}$ \\
\hline $81^{*}$ & 1.14 & 1.03 & I & 339 & 1.16 & 1.11 & B \\
\hline $311^{*}$ & 1.31 & 1.30 & D & $71-72^{*}$ & 1.15 & 1.04 & I \\
\hline $332^{*}$ & 1.22 & 1.09 & B & & & & \\
\hline $61-62^{*}$ & 1.08 & 1.01 & I & & & & \\
\hline $312^{*}$ & 1.14 & 1.07 & I & & & & \\
\hline $52^{*}$ & 1.20 & 1.10 & I & & & & \\
\hline $327^{*}$ & 1.29 & 1.03 & I & & & & \\
\hline $51^{*}$ & 1.24 & 1.07 & I & & & & \\
\hline
\end{tabular}

Linkages and Muktipliers of the Second cluster

\begin{tabular}{|c|c|c|c|c|c|c|c|}
\hline \multicolumn{8}{|c|}{ TOP-DOWN MATRXX } \\
\hline Belongs & $\boldsymbol{O}_{j}^{a}$ & $\boldsymbol{T}_{j}^{a}$ & $\begin{array}{l}\text { Linkage } \\
\text { s Type }\end{array}$ & Does not belongs & $O_{j}^{a}$ & $T_{j}^{a}$ & Linkages Type \\
\hline $312^{*}$ & 1.14 & 1.07 & I & 115 & 1.10 & 1.01 & I \\
\hline $331^{*}$ & 1.32 & 1.18 & B & 21-23 & 1.23 & 1.14 & D \\
\hline $114^{*}$ & 1.07 & 1.01 & I & $334^{*}$ & 1.37 & 1.50 & $\mathrm{~K}$ \\
\hline $71-72^{*}$ & 1.15 & 1.04 & I & $336^{*}$ & 1.11 & 2.18 & $\mathrm{~K}$ \\
\hline $52^{*}$ & 1.20 & 1.10 & I & $339^{*}$ & 1.16 & 1.11 & B \\
\hline $115^{*}$ & 1.10 & 1.01 & I & $51 *$ & 1.24 & 1.07 & I \\
\hline $61-62^{*}$ & 1.08 & 1.01 & I & $81^{*}$ & 1.14 & 1.03 & I \\
\hline $311^{*}$ & 1.31 & 1.30 & D & & & & \\
\hline $53-56^{*}$ & 1.07 & 1.21 & I & & & & \\
\hline $112 *$ & 1.22 & 1.05 & I & & & & \\
\hline $43-46^{*}$ & 1.15 & 1.45 & D & & & & \\
\hline $332 *$ & 1.14 & 1.09 & B & & & & \\
\hline $327^{*}$ & 1.29 & 1.03 & I & & & & \\
\hline $48-49^{*}$ & 1.19 & 1.15 & D & & & & \\
\hline \multicolumn{8}{|c|}{ Tja $=$ Multiplier of demand expansion } \\
\hline
\end{tabular}


Table 6

\begin{tabular}{|c|c|c|c|c|c|c|c|}
\hline \multicolumn{8}{|c|}{ BOTTOM-UP MATRIX } \\
\hline Belongs & $o_{i}{ }^{a}$ & $\boldsymbol{T}_{i}^{a}$ & $\begin{array}{c}\text { Linkages } \\
\text { Type }\end{array}$ & $\begin{array}{l}\text { Does not } \\
\text { belongs }\end{array}$ & $o_{i}{ }^{a}$ & $\boldsymbol{T}_{i}^{a}$ & $\begin{array}{c}\text { Linkages } \\
\text { Type }\end{array}$ \\
\hline $61-62 *$ & \multicolumn{2}{|l|}{1.09} & 1 & 114 & 1.07 & 1.01 & 1 \\
\hline 311* & 1.31 & 1.48 & $\mathrm{k}$ & 336 & 1.13 & 1.18 & $\mathrm{~K}$ \\
\hline $339 *$ & \multirow{2}{*}{$\begin{array}{l}1.17 \\
1.08\end{array}$} & \multirow[t]{2}{*}{1.07} & 1 & 43.46 & \multirow[t]{2}{*}{1.16} & 1.08 & D \\
\hline $53-56 *$ & & & D & & & & \\
\hline $51 *$ & 1.25 & 1.02 & 1 & & & & \\
\hline 81* & 1.15 & 1.07 & I & & & & \\
\hline $334 *$ & 1.34 & 1.23 & $\mathrm{~K}$ & & & & \\
\hline $331 *$ & 1.34 & 1.16 & 1 & & & & \\
\hline $312 *$ & 1.15 & 1.11 & 1 & & & & \\
\hline $327 *$ & 1.31 & 2.23 & B & & & & \\
\hline $48-49 *$ & 1.22 & 1.23 & $\mathrm{~K}$ & & & & \\
\hline $71-72 *$ & 1.16 & 1.01 & I & & & & \\
\hline $332 *$ & 1.23 & 1.02 & 1 & & & & \\
\hline $115 *$ & 1.11 & 1 & I & & & & \\
\hline $21-23 *$ & 1.25 & 1.9 & $\mathrm{k}$ & & & & \\
\hline $112 *$ & 1.23 & 1.02 & I & & & & \\
\hline $52 *$ & 1.22 & 1.08 & 1 & & & & \\
\hline & & kages $\alpha r$ & d Muktipli & sof the Sec & cluster & & \\
\hline Belongs & $o_{i}{ }^{a}$ & \begin{tabular}{l|}
$\boldsymbol{T}_{i}^{a}$ \\
\end{tabular} & $\begin{array}{c}\text { Linkages } \\
\text { Type }\end{array}$ & $\begin{array}{l}\text { Does not } \\
\text { belongs }\end{array}$ & $o_{i}{ }^{a}$ & $\boldsymbol{T}_{i}^{a}$ & $\begin{array}{c}\text { Linkages } \\
\text { Type }\end{array}$ \\
\hline $336 \times$ & 1.13 & 1.18 & $\mathrm{~K}$ & 114 & 1.07 & 1.01 & \\
\hline $52 *$ & 1.22 & 1.08 & I & $21-23$ & 1.25 & 1.9 & $\mathrm{~K}$ \\
\hline $332 *$ & 1.23 & 1.02 & I & 331 & 1.34 & 1.16 & 1 \\
\hline 112* & 1.23 & 1.02 & I & 339 & 1.17 & 1.077 & I \\
\hline $21-23 *$ & 1.25 & 1.9 & $\mathrm{~K}$ & 43.46 & 1.16 & 1.08 & D \\
\hline 71-72* & 1.16 & 1.01 & I & & & & \\
\hline $327 *$ & 1.31 & 2.23 & B & & & & \\
\hline $53-56 *$ & 1.08 & 1 & D & & & & \\
\hline $81 *$ & 1.15 & 1.07 & 1 & & & & \\
\hline $334 *$ & 1.34 & 1.23 & $\mathrm{~K}$ & & & & \\
\hline $115 *$ & 1.11 & 1 & 1 & & & & \\
\hline 311* & 1.31 & 1.48 & $\mathrm{~K}$ & & & & \\
\hline $312 *$ & 1.15 & 1.11 & 1 & & & & \\
\hline $48-49 *$ & 1.22 & 1.23 & $\mathrm{~K}$ & & & & \\
\hline $61-62 *$ & 1.09 & 1.06 & I & & & & \\
\hline $51 *$ & 1.25 & 1.02 & I & & & & \\
\hline oja $=$ Multipli & f producti & & $T j a=$ & Iultiplier of & 1and expar & & \\
\hline nked sectors & רol & & & & & & \\
\hline
\end{tabular}




\section{Conclusions}

The results have shown that, at both spatial and sectoral levels, contrary to the top-down regional matrix the sectors and economic structure in the bottomup regional matrix are theoretically and statistically coherent. This allows us to conclude the importance of considering the economic space as a fundamental element in the construction of regional input-output matrices.

A key element in this methodology is the type of regionalization that divides the economic sub regions and explains how they are integrated. The spatial economic functional units (SEFU, which do not consider political or natural spaces, as representations of the economic behavior on space, are essential. A naïve view of economic space is that in which the economic behavior is bounded to a political, natural or administrative space, leading us to misleading view of the real economic behavior on regions and cities. This view also alters the effectiveness and efficiency of the decision-making process and attempts to impulse regional economic growth and social development.

We consider this research has demonstrated the importance of taking into account the spatial distribution of the economic sectors within the region, through sub regions for the construction of a regional input-output matrix using a bottom-up approach, even with the lack of regional data, in order to create a closer view of the real regional economic performance and development.

This approach, compared to the top-down, offers richer and more realistic information of the behavior of the analyzed sectors within sub-regions and cities, not only through the number of observed productive chains in our analysis, but also through its meaningful industrial and services activities, classifying their economic linkages, in accordance to the existing economic specialization and diversification of the economic sub-regions of Sonora. Furthermore, this analysis is also consistent with the sectorial economic structure and its linkages and multiplier effects.

It is obvious the need to identify the location, of production and consumption of the economic activities taking place in order to define the economic linkages of the regional structure and at a sub-regional level. Without their inclusion, the analysis produces an aggregated region without space under the assumption that it behaves similar to the nation.

Even though this is an exploratory essay that tries to find alternative methodologies to the traditional top-down approach by using bottom-up perspectives, it is still under development. We believe we have presented solid elements to support our view and the advantages for continuing our research and for the achievement of a methodological proposal from a regional and territorial development perspective.

This methodology needs to be improved, especially through the elaboration of regional economic accounts so as to make them coherent with the national accounts of Mexico. It is also evident the need to construct a regional data base at a national level, to broaden the availability of information and thus expand 
the available tools of regional analysis. This should be done as the literature recommends, especially when it comes to the construction of regional make and use tables.

Besides, we also need a deeper analysis and estimation of the economic interactions, or, in other deepen into the estimation of inter-regional trade coefficients to get a sound estimate of sales and purchases between sub regions and regions, given the limitation of information and specific data for this type of analysis. Thus, the economic interaction index according to the economic space interpretation has to be reviewed. The existence of methodologies and techniques and also a new regional model have to be developed through a spatial perspective, (a multiregional mode) which implies taking into account the intra-regional and inter regional economic interdependencies.. It is likely that the incorporation of a principal components analysis and of spatial econometrics might improve it.

Furthermore, it is also needed to have a more robust statistical analysis to prove the advantages of our approach compared to the traditional one. We already have important and favorable advances concerning the improvement of this methodology, in terms of the mentioned needs. We expect them to be published soon.

Finally, it is important to stress out that this work is part of a line of research developed by the CEDRUS organization over a long period of time, and it has been applied to the construction and analysis of regional input-output matrices. This has already opened new research proposals for spatial and economic applied studies in different areas in economics.

\section{References}

Asuad Sanén, Normand Eduardo, Sánchez Gamboa José M and Garduño Maya, Karina (2015), A comparative analysis for constructing regional input-output tables, for Sonora, Mexico, from the bottom-up approach, its methodology and advantages over the top-down approach. (23rd IIOA Conference in México City, 2015)

Asuad Sanén, Normand Eduardo, Vásquez, Cristina and Quiñones (2015), Manufacturing Clusters in unctional economic North -Central region of México: A spatial approach using input-output analysis,

Asuad Sanen Normand Eduardo, (2014) Pensamiento económico y espacio- Economic Thinking and Space, Colección economía regional y urbana,Volumen Primero, Facultad de Economía de la UNAM.

Asuad Sanen Normand Eduardo, (2007a) Un ensayo teórico y metodológico sobre el proceso de concentración económica espacial y su evidencia empírica en la región económica megalopolitana de 1970 a 2003 y sus antecedentes

Asuad Sanen Normand Eduardo, (2007b) Una propuesta metodológica para la delimitación de regiones económicas a través de un índice de interacciones económicas, el caso de la región Noreste del país.

Asuad Sanen Normand Eduardo, (2001) Economía regional y urbana: Introducción a las teorías, técnicas y metodologías básicas.-Urban and Regional Economics. An introduction to the theories, technics and basic Methodologies, Benemérita Universidad Autónoma de Puebla, Colegio de Puebla, Asociación de Ex -alumnos de economía de la FE-UNAM.

Garduño Maya Karina, Asuad Sanén Normand Eduardo and Sanchez Gamboa José M., (2016), Exploratory analysis of the use of a multiregional input-output matrix for the analysis of the main urban impacts of the new México city airport, IIOA 24rd Conference Seul, Korea 
Revista Mexicana de Economía y Finanzas,Vol. 13 No.2, (2018), pp. 137-174

Brand, Steven, (2012), A Note On Methods Of Estimating Regional Input-Output Tables: Can The Fleg Improve The Ras Algorithm?, The busines school whith Plymouth University

Bracamonte Sierra Álvaro and Sánchez G. José Manuel "Matriz Insumo Producto para el Estado de Sonora, 2011: Actualización y Regionalización Estadística". Gobierno del Estado de Sonora, Secretaria de Economía, Hermosillo Sonora, Julio 2011 Consejo para la Promoción Económica de Sonora (COPRESON)

Calicó et al, (2003), La matriz interregional del centro occidente de México. En Insumo producto regional y otras aplicaciones, UAMA, IIES, UNAM, U de G. Chapa Cantú, J., Ayala E. y Hernández D. (2009) Modelo de insumo producto para el noreste de México. Ciencia UANL, Vol. 12, No.4

Cruz, Roberto. 2008. Matriz de insumo-producto de la economia de Oaxaca e identificacion de sus flujos intersectoriales mas importantes, tesis de maestria en Economia Regional, Universidad Autonoma de Coahuila.

Dávila, F. (2002), Matriz de insumo-producto de la economía de Coahuila e identificación de sus flujos intersectoriales mas importantes, Economía Mexicana. Nueva Época, Vol. XI, núm. 1.

Dávila, F. (2015), Coordinador, Modelos interregionales de insumo producto de la economía mexicana, Editorial Miguel Ángel Porrúa, Universidad Autónoma de Coahuila y Universidad Autónoma de Nuevo León, México, DF.

De la Fuente Fernández Santiago, Apuntes de Componentes principales, UAM, Madrid, 2011.

Feser, E. J. y Berman, Edward M., National industry cluster templates: A framework for applied regional cluster analysis, Regional Studies, vol. 34-I, 2000, pp. 1-19.

Garduño, Karina, Asuad Sanén, Normand E. and Sánchez Gamboa José M. (2015), Airport Cluster in México City, a spatial approach using a regionalized input-output matrix from top-down approach, IIOA 23rd Conference Mexico City. INEGI (2009), Censo económico 2009. Sonora.

K. Burgos M. (2007), Analisis de multiplicadores y elasticidades para la economia chilena base 2003, mediante un enfoque input-output, Universidad del Bio-Bio, F.C.E. Concepción, Chile.

Lahr M. L. (1993). A Review of Literature Supporting the Hybrid Approach to Constructing Regional Input-Output Models. Economic Systems Research, 5:pp. 277-293.

Lahr M. L. (2001). A Strategy for Producing Hybrid Regional Input-Output Tables. In Lahr M. L. and Dietzenbacher (eds.), Input-Output Analysis: Frontiers and Extensions, Palgrave, London, pp. 1-31.

Maya, Marcos, Asuad Sanen, Normand E. and Sánchez, Gamboa José M., (2015), Regional Vertical specialization of the automotive chain in the Central North región of México and its main effects on regional production structure: A spatial approach using an inputoutput regional table, IIOA 23rd Conference Mexico City.

Richardson H. W. (1972). Input-Output and Regional Economics. Weidenfeld and Nicolson, London, UK.

Sánchez Gamboa José Manuel and Bracamonte J, (2006), Aglomeraciones industriales y desarrollo económico. El caso de Hermosillo Frontera norte vol.18 no.36 México jul./dic. 2006

Secretaria de Economía, Gobierno del Estado de Sonora, 2011, Matriz de Insumo-producto para el Estado de Sonora, Actualización y Regionalización estadística, Sonora Hermosillo, 30 de Julio de 2011

Vazquez, Ruiz Cristina, Asuad Sanén Normand Eduardo, and Zafra, Krista, (2016), Economic interactions productive chains and formation of manufacturing clusters in the functional economic North Central region of México: a case of regional input-output approach, IIOA 24rd Conference Seul, Korea

West G. R. (1990). Regional Trade Estimation: A Hybrid Approach. International Regional Science Review, 13: 103-11 
168 Nueva Época REMEF (The Mexican Journal of Economics and Finance)

\section{Attachment I}

Table No.4

Economic linkage analysis: forward \& backward linkages of the matrix of Sonora using a top-bottom approach

\begin{tabular}{|clccc|}
\hline No & \multicolumn{1}{c}{ Sectors } & $\begin{array}{c}\text { Forward } \\
\text { Linkages }\end{array}$ & $\begin{array}{c}\text { Backwad } \\
\text { Linkages }\end{array}$ & Type of Sectors \\
\hline 112 & Animal breeding and their production & 0.08 & 0.11 & Independent sectors \\
114 & Fishing and hunting & 0.13 & 0.01 & Independent sectors \\
115 & Services related to agricultural and forestry activities & 0.24 & 0.01 & Independent sectors \\
2 & Basic Industry & 0.03 & $>2.0$ & Base sector \\
311 & Food industry & 0.04 & 1.54 & Drag Sectors \\
312 & Beverage and tobacco industries & 0.11 & 0.4 & Independent sectors \\
327 & Nonmetallic mineral products manufacturing & 0.14 & 0.25 & Independent sectors \\
331 & Basic metal industry & 1.08 & 0.44 & Base sectors \\
332 & Metal products manufacturing & 1.50 & 0.25 & Base sectors \\
334 & Computers and other electronic equipment. & $>2.0$ & 1.42 & Key sectors \\
336 & Manufacturing of transportation equipment & $>2.0$ & $>2.0$ & Key sectors \\
339 & Other manufacturing industries & 1.45 & 0.2 & Base sectors \\
$43-46$ & Wholesale and retail activities & 0.54 & $>2.0$ & Drag Sectors \\
48 49 & Transportation, postal services and warehousing & 0.20 & 1.47 & Drag Sectors \\
51 & Mass media information & 0.13 & 0.69 & Independent sectors \\
52 & Financial and insurance services & 0.75 & 0.21 & Independent sectors \\
$53-56$ & Urban Services & 0.24 & 1.66 & Independent sectors \\
6 & Social Services & 0.01 & 0.70 & Independent sectors \\
7 & Cultural and recreational services & 0.19 & 0.49 & Independent sectors \\
8 & Other Services & 0.15 & 0.44 & Independent sectors \\
\hline
\end{tabular}

Graph 1

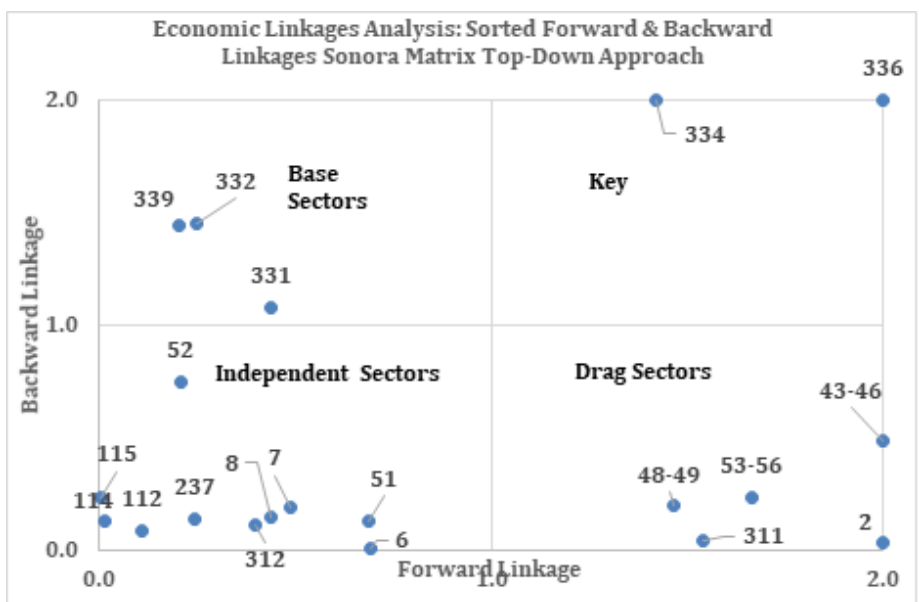




\section{Attachment II}

\begin{tabular}{|c|c|c|c|c|}
\hline \multicolumn{5}{|c|}{$\begin{array}{c}\text { Table No.5 } \\
\begin{array}{c}\text { Economic linkage analysis: forward \& backward linkages of the matrix of Sonora using a bottom-top } \\
\text { approach }\end{array}\end{array}$} \\
\hline No & Sectors & $\begin{array}{l}\text { Forward } \\
\text { Linkages }\end{array}$ & $\begin{array}{l}\text { Backwad } \\
\text { Linkages }\end{array}$ & Type of Sextors \\
\hline 712 & Animal breeding and their production & 0.07 & 0.11 & Thdependent sectors \\
\hline 114 & Fishing and hunting & 0.02 & 0.08 & Independent sectors \\
\hline 115 & Services related to agricultural and forestry acfivites & 0.05 & 0.00 & Independent sectors \\
\hline 2 & Basiclndustry & 2.00 & 2.00 & Keysectors \\
\hline 311 & Food industry & 2.00 & 2.00 & Keysectors \\
\hline 312 & Beverage and tobacco industries & 0.30 & 0.47 & Independent sectors \\
\hline 327 & Nonmetallic mineral products manufacturing & 0.28 & 2.00 & Drag Sector \\
\hline 331 & Basicmetal industry & 0.19 & 0.58 & Independent sectors \\
\hline 332 & Metal products manufacturing & 0.15 & 0.08 & Independent sectors \\
\hline 334 & Computers and other electronic equipment. & 2.00 & 1.45 & Keysectors \\
\hline 338 & Manufacturing of transportation equipment & 1.35 & 1.11 & Keysectors \\
\hline 339 & Other manufacturing industries & 0.29 & 0.34 & Independent sectors \\
\hline $43-46$ & Wholesale and retail activifes & 2.00 & 0.38 & Base sector \\
\hline 48,49 & Transportafion, postal services and warehousing & 1.47 & 1.08 & Keysectors \\
\hline$\overline{51}$ & Mass media information & 0.64 & 0.11 & Independent sectors \\
\hline 52 & Financial and insurance servioes & 0.10 & 0.32 & Independent sectors \\
\hline $53-56$ & Urban Services & 1.88 & 0.00 & Base sector \\
\hline 6 & Social Servioes & 0.74 & 0.27 & Independent sectors \\
\hline 7 & Cultural and recreational services & 0.42 & 0.05 & Independent sectors \\
\hline 8 & Other Servioes & 0.48 & 0.37 & Independent sectors \\
\hline
\end{tabular}

Graph 2

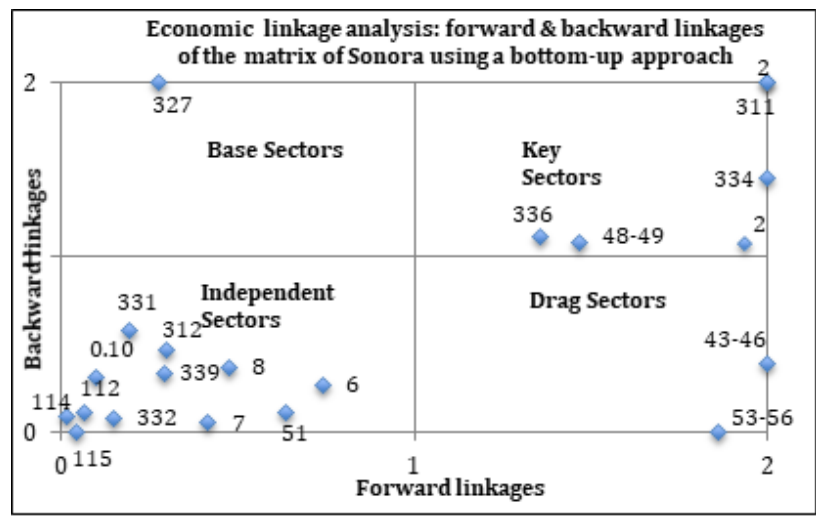




\section{Attachment II}

\section{The Methodology of Flegg, Weber and Elliot}

The methodology of Flegg, Weber and Elliot begins with the estimation of the location ratio $S L Q_{i j}$, followed by the identification of the regional industrial specialization and the estimation of the crossed industrial location coefficient $C I L Q_{i j}$, which measures the relative industrial specialization of the region. Subsequently, it estimates the relative size of the region compared to the nation, through the application of the modified Flegg et al coefficient, $F L Q_{i j}$, which aims at measuring the degree of supply of a region, $t_{i j}$, so that, if $F L Q_{i j}$ is greater or equal to 1 , the regional supply would be equal to 1 , and if it is less than 1 , it takes the value of that coefficient. This means that if the coefficient is equal to 1 in any economic sector of the region, it behaves as seller. Otherwise it is a buyer, in the proportion indicated by the differences that arise of the value of its coefficient minus 1 .

Once the degree of regional supply is known, the technical production coefficients $r_{i j}$ are estimated for each economic sector and sub-sector, which in turn is a function of the product of the regional supply coefficients by the national coefficients of production $r_{i j}=t_{i j} \times a_{i j}$. Finally, the amount of both regional purchases and sales of inputs is estimated. They are a function of each technical coefficient of production for each sub region multiplied by total value added and the total production, respectively. Through the RAS method, we equilibrate the purchases and sales of the regional matrix.

\section{Attachment III}

\section{The identification of regional links and economic interactions}

Traditionally, economic interactions are estimated through real or probabilistic flows. Real flows require availability of data, which in the case of economic activities is generally not available. Thus, it is common to use proxy variables, such as passenger flows, traffic flows, flows and telephone calls in order to identify economic interactions. Probabilistic flows are based on simple probability in which gravity models are commonly used, given its common utilization even in international trade analysis to determine trade flows between countries ${ }^{21}$. Gravitational models have also been used for the estimation of technical coefficients of regional production, mainly when two or more regions are linked economically, which requires the calculation of technical coefficients for the construction of interregional matrices. Furthermore, since the creation of the first works in the field, the interest and proposals to develop gravity models as a tool for the estimation of regional matrixes, needs more improvement ${ }^{22}$.

However, without denying the importance of this intention, the challenges and difficulties that we have to overcome in order to apply it, we consider that the initial problem arises from how this model is disaggregated sectorial and spatially, with the purpose to implementing it adequately so as to handle huge amounts of data at different levels of spatial scale. In theory, the best way is to

\footnotetext{
${ }^{21}$ Ver Asuad 2001, pp. 209-225

${ }^{22}$ Ver Miller and Blair, pp . 364 y 365, Op. Cit.
} 
disaggregate data at sectorial level. However, this depends on the purpose of the analysis and the number of sectors economic activity in the input-output matrix. Nevertheless, at the spatial level it is absolutely necessary to disaggregate at a locality level and spatial levels corresponds to the disaggregation at class level of activity.

Consequently, in order to be more precise, the identification of the sectorial economic activities of each sub-region, we proceeded to identify the productive chains of economic activity in each sub-region, as well as their productive links, with the intention to know their specific location and spatial distribution at locality level. Then, the gravity model was applied in part, considering just the weight and importance of the economic activities of the sub-regional productive chains. Hence we assume, that it could be more specific if we try to identify a trade pattern among regions, considering the sizing of the weight or their relative importance of production economic activities measured by an economic interaction index, through a statistical association between sub-regions, it is possible to infer the possible trade patterns that would emerge from economic flows between sub-regions.

\section{The Economic interaction Index}

This index measures the economic interaction between a pair of sub regions and is obtained by multiplying the matrix of partial correlations of the economic activities and the matrix of the crossed participation of these activities of the sub regions.

$$
\begin{gathered}
E=\left(e_{i j}\right) \\
\text { Where: } \\
e_{i j}=r_{i j} \times p_{i j} \\
r_{i j}=R_{i j}^{2} p_{i j} \forall i j
\end{gathered}
$$

Where: The multiplication is element by element

$$
\mathrm{E}=\left(\begin{array}{cc}
e_{11} & e_{1 n} \\
e_{n 1} & e_{n n}
\end{array}\right)=\left(\begin{array}{cc}
r_{11} \times p_{11} & r_{1 n} \times p_{1 n} \\
r_{n 1} \times p_{n 1} & r_{n n} \times p_{n n}
\end{array}\right)
$$

So $e_{i j}[0,1]$ and is called index economic interaction between the two sites ij. Here it is worth noting that $\mathrm{E}$ is also a symmetric matrix.

Then if we standardized the interaction economic index we have the following:

$$
\begin{gathered}
E=\left(e_{i j}^{*}\right) \\
e_{i j}^{*}=\frac{e_{i j}-\operatorname{Min}\left(e_{i j}\right)}{\operatorname{Max}\left(e_{i j}\right)-\operatorname{Min}\left(e_{i j}\right)}
\end{gathered}
$$




$$
\begin{gathered}
\text { So if } i=j=1 \\
\text { So if } i \neq j
\end{gathered}
$$

The methodology that comprises the main steps of the application of the economic index is the following:

1. It is determined the statistical association between a couples of sub regions, through the Pearson correlation coefficient, so with these results, it was built a correlation matrix between economic sub regions .

2. It is constructed a second matrix, based on the cross participation of the correlation index between economic sub regions, taking into account the intensity of the correlation between pair of them.

3. It is multiply the correlation matrix with the cross participation matrix, and is standardized their results, in order to obtain the economic interaction matrix between economic sub regions.

\section{Attachment IV \\ Identification of regional clusters, economic linkages and their multi- plier effects}

The methodology for the identification of clusters and the sectors that integrate them as well as their economic links and economic performance, is based on the use of the principal components analysis combined with the application of the traditional multipliers of input-output. The statistical analysis consists of a multivariate analysis that allows for a synthetic description of the structure and the interrelations of a set of variables of study. For its application we rely on the proposals of Feser and Bergman (2000) and in the work of Sánchez Gamboa and Bracamonte (2006).

The principal components analysis is a process whose purpose is to obtain and represent new variables in a reduced way. These new variables are defined as principal components or factors, which correspond to linear combinations of the variables that are not correlated, presenting them in a decreasing order of importance. In the literature, there are several methodologies for obtaining such combinations. In this case they were estimated searching for the maximum variability of the new variables and their adequate graphical representation. The use of this methodology was applied in order to determine the integration and linkage of the economic sectors in clusters derived from the regional matrices constructed. The stages that are the following:

1) Integration of the clusters (percentage explained by the component)

This analysis was performed with the correlation matrices of the data, in order to obtain the sectors that integrate each of the clusters derived from the regional I-O matrices constructed with both bottom-up and top-down approaches. These matrices were constructed using the purchases and sales matrices of the studied sectors, where the links between the nxn sector pairs are shown. The columns of 
this matrix represent the relative link patterns between sectors. Subsequently, the principal components of the data were identified through the estimation of the values and eigenvectors and there were interpreted by the orthogonal rotation of the factor axes, through the Varimax method, thereby the correlation of each of the variables was closest to 1 with only one factor and close to 0 with the rest of them. Also, to facilitate the decision regarding the number of rotated components, the relative proportion of the explained variance of each component with respect to the total of the data was taken. The results obtained provided a measure of the relative relation between a given sector and the derived factor, thus a high own value in the factor of that branch means that it belongs economically to that cluster. Finally, it should be mentioned that out of the total of the identified components, the first ones were selected, given that they are representative of all the identified ones.

\section{2) Linking (graphical analysis and component chains)}

The second stage of the analysis is oriented to the analysis of linkage between the sectors in each identified component, as well as their relationships, deriving from the regional matrices constructed under the different approaches. Thus, we use the Chenery- Watanabe economic linkage analysis presented above, and also performing a graphical analysis based on the results obtained from the analysis of main components relying on the graphs of correlation circle and on the coordinates of individuals.

Correlation circle: This allows us to plot the correlation between the main components and the original variables, where, the $\mathrm{x}$ axis is represented by the principal component 1 (Pc1) and the (y) axis by the principal component 2 . This analysis is done for each of the identified components, according to the information coming from the regional matrices constructed with both approaches.

Coordinates of individuals: This graph is obtained by multiplying the original data matrix by the principal components matrix, in order to plot them in the correlations circle and to observe the relationships between sectors and principal components in each regional matrix that had been analyzed.

The combined analysis of the circle of correlations and the coordinates of individuals allowed us to establish relationships between sectors, the position of a sector in the coordinates of individuals indicates that this sector is linked to the sector (s) found in that same position in the correlation circle.

The analysis of principal components can be expressed in matrix notation ${ }^{23}$ in a compact way, where y corresponds to the main components; $\mathrm{A}$, is the matrix of coefficients or weights; $\mathrm{x}$, is the vector containing the original variables, and is obtained by multiplying the weight matrix by that of the original variables. This is denoted as:

$$
y=A x
$$

\footnotetext{
${ }^{23}$ De la Fuente Fernández Santiago, Apuntes de Componentes principales, UAM, Madrid,
} 2011. 


$$
\mathrm{y}=\left(\begin{array}{c}
y_{1} \\
y_{2} \\
\ldots \\
y_{4}
\end{array}\right) ; A=\left(\begin{array}{cccc}
a_{11} & a_{12} & \ldots & a_{1 n} \\
a_{21} & a_{22} & \ldots & a_{2 n} \\
\ldots & & & \\
a_{n 1} & a_{n 2} & \ldots & a_{n n}
\end{array}\right) ; x=\left(\begin{array}{c}
x_{1} \\
x_{2} \\
\ldots \\
x_{4}
\end{array}\right)
$$

Just like there are uncorrelated variables, the vector y is equal to its variance $\lambda$, then matrix $\mathrm{A}$ is transformed into matrix $\Delta$, which collects the coefficients as variances of $\mathrm{y}$, as follows

$$
\begin{gathered}
y_{1}=\lambda_{1} \\
y_{2}=\lambda_{2} \\
\quad \ldots \\
y_{4}=\lambda_{4}
\end{gathered} ; \Delta=\left(\begin{array}{cccc}
\lambda_{1} & 0 & \ldots & 0 \\
0 & \lambda_{2} & \ldots & 0 \\
\ldots & & & \\
0 & 0 & \ldots & \lambda_{4}
\end{array}\right)
$$

Where:

$\Delta=\operatorname{Var} Y=A^{\prime} \operatorname{Var} X(A)$

Since A is a square matrix, the percentage of total variance of a component is expressed as a share of the total variance:

$$
\frac{\lambda_{i}}{\operatorname{sum}_{i=1}{ }^{n_{\lambda}}}=\frac{\lambda_{i}}{\operatorname{sum}_{i=1}{ }^{n} \text { Varx }_{i}}
$$

Finally, in order to analyze the economic performance of the clusters, the multipliers of production and the expansion of demand are used, which according to K Burgos (2007), in the case of an increase in the demand of sector $\mathrm{j}$, another increase on the productive sectors will happen:

$$
O_{j}^{\alpha}=\sum \alpha_{i j}
$$

Where:

$\alpha_{i j}$ : the elements of the inverse matrix of Leontief

Thus, in the case of the demand expansion, we have:

$$
T_{j}^{\alpha}=\sum \alpha_{i j}
$$

